\title{
La participación de los trabajadores en la calidad total: nuevos dispositivos disciplinarios de organización del trabajo
}

\author{
Arturo Lahera Sánchez \\ Universidad Complutense de Madrid \\ alaheras@cps.ucm.es
}

RESUMEN

Las ciencias sociales del trabajo han desarrollado en la última década un amplio debate académico y empresarial sobre la posible emergencia de nuevos modelos industriales en las empresas, centrados en la implantación de culturas organizativas o empresariales supuestamente rupturistas con las tradicionales prácticas tayloristas de organización del trabajo. Entre estas transformaciones destaca la apuesta gerencial por establecer una gestión participativa de los recursos humanos (empowerment) que permita, por un lado, aprovechar los conocimientos empíricos de los trabajadores en la mejora y perfeccionamiento de los procesos de fabricación y, por otro lado, garantizar su mayor implicación en la consecución de los objetivos empresariales, mediante el diseño de una nueva "cultura organizativa de la calidad». Esta participación, centrada en la autonomía en el puesto de trabajo, es la base sobre la que se está construyendo una nueva estrategia competitiva basada en políticas de aseguramiento de la calidad de la producción, las cuales están provocando transformaciones en los dispositivos de organización y de inspección gerencial del trabajo. Sin embargo, el resultado efectivo de esta consecución de la calidad ha supuesto el diseño e implantación de nuevas prácticas tayloristas y de una vigilancia incrementada sobre la actuación de los trabajadores, con lo que la definición gerencial de la participación ha modelado, y limitado, ésta como un dispositivo de expropiación de los conocimientos y experiencia de aquéllos, al tiempo que ha supuesto la construcción de una nueva disciplina y sistema de control detallado de su rendimiento productivo y de intensificación de su actividad, tal y como ejemplifican los contenidos reales de las políticas de reestructuración productiva y organizativa realizadas en empresas fabricantes de máquinas-herramienta de Euskadi durante la segunda mitad de la década de los años noventa (1994-2000).

Palabras clave: Participación de los Trabajadores, Calidad Total, Taylorismo, Modelos Productivos, Disciplina Industrial, Cultura Empresarial, Empowerment, Máquina-Herramienta. 


\section{INTRODUCCIÓN*}

Uno de los ejes fundamentales del desarrollo de la sociología del trabajo, así como de otras ciencias sociales del trabajo, se ha centrado en reflexionar sobre el grado de vigencia o de superación de la tradicional organización del proceso de trabajo representada por el taylorismo, tanto por sus principios teóricos o discursivos como por las prácticas empresariales a las que dio lugar, todo ello en relación a sus efectos sobre las condiciones de trabajo y a sus ventajas o desventajas en la consecución de los objetivos productivos y de calidad de las empresas (Castillo, 1991). Pues bien, en la última década volvió a aflorar de una manera destacada una reflexión sobre la posible emergencia de nuevos modelos y conceptos productivos en las empresas, es decir, una supuesta nueva articulación de principios o paradigmas organizativos para reorganizar los procesos de producción en los que se ha enfatizado la necesidad de la participación destacada de los trabajadores y la necesaria ruptura con la vieja y tradicional división del trabajo (Boyer y Freyssenet, 1996; Durand, Stewart y Castillo, 1999), haciendo mayor hincapié en la implicación de los trabajadores en la gestión autónoma de sus puestos de trabajo, así como en incrementar la vinculación «armónica y unitaria» de la fuerza de trabajo en la consecución de los objetivos productivos diseñados por las gerencias para garantizar la supervivencia empresarial y del empleo (Smith, 1989; Tuckman, 1995).

La participación aparece así como un dispositivo o tecnología social (acuñadora de prácticas y comportamientos en los sujetos; Ping, Ashmore y Mulkay, 1992) que puede contribuir a incrementar la eficiencia de la organización, una reducción de costes, un incremento de la productividad y de la calidad, todo ello mediante la delegación hacia los trabajadores del poder, la autoridad y la capacidad de tomar decisiones organizativas. Esta participación pretende potenciarles, capacitarles y dotarles de las herramientas, los recursos y la discrecionalidad que les permitan avanzar en los intereses de la organización (Edwards y Collinson, 2002), tal y como sintetiza el concepto empresarial de empowerment, que se ha convertido académica y profesionalmente en el catalizador metafórico de las propuestas de gestión participativa de los recursos humanos en la última década (Storey, 1995; Potterfield, 1999; Harley, 1999; Blyton y Turnbull, 1992). Al mismo tiempo, esta noción de la participación de los trabajadores pretende avanzar en la consecución del compromiso de éstos con los objetivos empresariales: colaborando, por tanto, en lograr simultáneamente el fun-

\footnotetext{
* Las reflexiones contenidas en este artículo proceden de la discusión teórica y del trabajo de campo realizados en mi tesis doctoral, La emergencia de nuevos modelos productivos y la participación de los trabajadores: Diseño e implantación de conceptos antropocéntricos de producción en empresas fabricantes de máquinas-herramienta (Lahera Sánchez, 2000), dirigida minuciosa y cuidadosamente por el profesor Juan José Castillo. Agradezco sinceramente las recomendaciones y correcciones sugeridas por el evaluador de la REIS, que me han permitido condensar, profundizar y completar mi interpretación crítica sobre el fenómeno de la participación de los trabajadores. Para Nuria Íñigo Bejarano, quien ha compartido vitalmente la realización completa de esta investigación, la cual ha sido consecuencia de su esfuerzo y compromiso.
} 
cionamiento fluido de la producción y la superación de los tradicionales conflictos en el taller (Gaudemar, 1991: 92; Cressey y Di Martino, 1991), buscándose así el incremento de la motivación y rendimiento de los propios trabajadores (Legge, 1995). Esta apuesta participativa se justifica gerencialmente por la necesidad de integrar a los trabajadores en los objetivos empresariales mediante su asunción de mayor responsabilidad en la toma de decisiones (Hale, 2000; Clutterbuck, 1994).

Precisamente, durante los años noventa (1994-2000), un número destacado de empresas vascas fabricantes de máquinas-herramienta han desarrollado y diseñado nuevas formas de gestión de los recursos humanos, habiendo comenzado a aplicar dispositivos discursivamente participativos. Estas pretendidamente novedosas estrategias han estado orientadas por los contenidos de las políticas diseñadas conjuntamente por el Gobierno Vasco (Eusko Jaurlaritza) y la Asociación (empresarial) de Fabricantes de Máquinas-Herramienta (AFM) para reestructurar este sector tras las sucesivas crisis cíclicas que ha sufrido en las últimas tres décadas (Programa de Competitividad del Clúster de la Máquina-Herramienta). Este programa de reconversión industrial se ha basado, entre otras medidas, en propiciar en estas empresas la consecución de la calidad, el aseguramiento de que las máquinas fabricadas tienen una elevada incorporación de calidad que satisface plenamente las exigentes demandas de un mercado segmentado, como el principio empresarial y comercial destacado para la supervivencia de los centros productivos ${ }^{1}$ (AFM, 1985 y 1990; Gobierno Vasco, 1992 y 1994; SPRI, 1994). En esta reestructuración sectorial, las políticas empresariales de aseguramiento de la calidad aparecerán como discurso justificador de las prácticas de transformación «participativa» del contenido de las tareas y funciones a desempeñar por parte de los trabajadores de estas empresas.

La propuesta investigadora recogida en este artículo se centrará en rastrear críticamente los intereses, objetivos e interpretaciones que los organizadores de la producción (gerentes, directores, ingenieros...) construyen en su definición de «calidad» y de «participación», en la supuesta delegación hacia los operadores de la capacidad o poder de intervenir en la toma de decisiones productivas (empowerment ${ }^{2}$ ), para comprender (y

\footnotetext{
1 Tras la reconversión estructural del sector durante la pasada década, las empresas fabricantes de máquinas-herramienta de la economía española se caracterizan por tener un alto grado de capacidad e innovación tecnológica en comparación con otros sectores; por desarrollar una clarísima actividad exportadora (el 60-70\% de la producción se exporta a países como Alemania, Francia, EE.UU., China...), siendo, por tanto, un sector muy competitivo internacionalmente; por estar conformado históricamente sobre capital autóctono (básicamente en Euskadi, donde se concentra más de las dos terceras partes de la producción); y por su importancia estructural al fabricar recursos técnicos que posteriormente emplearán otros sectores para producir sus bienes, con lo que una fabricación de avanzadas, potentes y fiables máquinas-herramienta supone introducir en la cadena productiva posibilidades de incrementos de productividad y calidad, multiplicándose global y económicamente los efectos y resultados productivos de este sector (productor de productividad).

2 La traducción literal al castellano de empowerment es la de autorizar formalmente a un sujeto, otorgándole poder o autoridad, para la realización de un fin o un objetivo; otra de sus acepciones es precisamente el acto de posibilitar, potenciar o ca-
} 
deconstruir) las posibles mutaciones en la organización del trabajo, así como sus implicaciones en la modelación de dispositivos de control gerencial sobre la fuerza de trabajo: «Para superar la versión benigna de la gestión de la calidad es necesario comprometerse en un cuestionamiento radical de la forma en que la calidad es identificada y perseguida» (Wilkinson y Willmott, 1995: 16). El objetivo es avanzar exploratoriamente hacia la definición de una hipótesis de investigación en que se vincularán los métodos de aseguramiento de la calidad total con el diseño gerencial de nuevos dispositivos disciplinarios de control sobre los trabajadores, su actividad y su rendimiento.

Esta perspectiva de interpretación teórica sobre el carácter disciplinario de la participación de los trabajadores en el aseguramiento de la calidad, construida a partir de los resultados obtenidos en el trabajo de campo y de terreno en los talleres de cuatro empresas, Buruzagi (fabricante de tornos y rectificadoras $\mathrm{CNC}$ ), Berritzaile (fresadoras $\mathrm{CNC}$ ), Zuzendu (tornos CNC) y Eskulan (fresadoras convencionales y centros de mecanizado CNC), las tres primeras en Elgoibar (Guipúzcoa) y la última en Vitoria-Gasteiz (Álava), pretende contribuir al debate que desde las teorías del proceso de trabajo (labour process) persiguen reconstruir críticamente los orígenes, desarrollos y resultados de las continuamente reformuladas propuestas gerenciales de gestión de los recursos humanos difundidas internacionalmente en las últimas décadas (excelencia y liderazgo, producción ligera, aseguramiento de la calidad, reingeniería de procesos, empowerment...) (Wilkinson y Willmot, 1995; Sewell y Wilkinson, 1992; Jones, 1997; Thompson y Warhurst, 1998).

Precisamente, los contenidos efectivos de las prácticas gerenciales rastreadas en estas cuatro empresas vascas, especialmente significativas puesto que todas ellas se sitúan en una posición comercial e industrial destacada en los diferentes segmentos tecnológicos y productivos del sector de fabricación de máquinas-herramienta (Lahera Sánchez, 2000: capítulo 3), convergen o avanzan en la misma dirección de configurar gerencialmente la calidad como un nuevo dispositivo disciplinario y de intensificación del trabajo, como han reseñado diversas investigaciones internacionales dentro de esa tradición teórica del proceso de trabajo, lo que, si bien no supone poder generalizar necesariamente las experiencias rastreadas en estas empresas vascas analizadas, sí permite enfatizar su relevancia y significatividad al representar tendencias comunes y similares a las de otras experiencias a nivel mundial y español (Paniagua López, 1999; Tuckman, 1995; Delbridge, Turnbull y Wilkinson, 1992; Roberts y Corcoran-Nantes, 1995; Kerfoot y Knights, 1995), reforzando así el

pacitar (hacer competente o capaz) a los sujetos con los recursos y medios para obtener ese objetivo. Precisamente, el empleo de este concepto en el discurso managerial condensa ambas acepciones al enfatizar el carácter de otorgamiento por parte de la gerencia de la capacidad o autorización a los trabajadores para que empleen determinados recursos productivos para lograr los fines empresariales, señalando siempre que el poder originario reside en la propia gerencia. Este significado completo será el que se utilice a lo largo de este texto. [Véase para la traducción: The Oxford English Dictionary, Oxford, Oxford University Press.] 
potencial explicativo de esta hipótesis de interpretación sobre las políticas de aseguramiento de la calidad total en las empresas ${ }^{3}$.

\section{EL DISCURSO GERENCIAL SOBRE LA «CALIDAD»: LA DEFINICIÓN DE UNA CULTURA ORGANIZATIVA BASADA EN LA IMPLICACIÓN ACTITUDINAL DE LOS TRABAJADORES}

La adaptación y reestructuración productiva desarrollada en la última década en el sector de fabricantes de máquinas-herramienta ha pretendido afrontar una demanda cada vez más diversificada, apostando por una estrategia de fabricación de maquinaria «a medida» que se basa principalmente en un condicionante operativo: la consecución de la calidad total en las máquinas vendidas, que el producto satisfaga plenamente las demandas del cliente (Sarriés, 1994: 53-54). La definición empresarial de esta calidad total implica, en términos de la organización del proceso de trabajo:

"La responsabilidad de hacer las cosas bien hechas por uno mismo y por respeto a los otros compañeros; si cada persona hace sus tareas y trabajos con Calidad, no carga a otros compañeros con trabajo extra; no es justo asumir y responsabilizarse del trabajo mal hecho por otros; la Calidad Total es un compromiso de todos y también un derecho a ejercer las funciones propias de su cargo, dedicando energía a la superación personal en lugar de dedicar tiempo a la triste y desmotivante tarea de repetir las cosas mal hechas; hacer la propia tarea y cargarse el trabajo de revisar y rectificar lo mal hecho por otros no sólo no es justo, sino que trae problemas de coordinación, inquietud y nerviosismo de las personas responsables que se ven impotentes en cumplir sus funciones y además dedicar tiempo a arreglar las cosas mal hechas por otros; la gestión por la Calidad Total es un sistema justo y equitativo mediante el cual pueden desarrollarse las personas y las organizaciones; aceptar el reto de la Calidad implica deseo de superación, compromiso de hacer las cosas

\footnotetext{
3 Se emplearon diversas técnicas de investigación, de carácter cualitativo y participativo, para acceder a los espacios y situaciones reales de trabajo de las empresas que se han seleccionado en el trabajo de campo de esta investigación: análisis del trabajo, observación participante y entrevistas en profundidad, que han permitido obtener una interpretación global sobre el origen, el desarrollo, la implantación y los resultados de las transformaciones organizativas en el diseño del trabajo humano en las empresas fabricantes de máquinas-herramienta analizadas. Se realizaron así 80 entrevistas en profundidad a organizadores de la producción, representantes sindicales y trabajadores, al tiempo que se han reconstruido ocho puestos de trabajo, tanto de mecanizado como de montaje. Durante dieciséis meses (de marzo de 1998 a junio de 1999), la estancia continua y permanente en los talleres de mecanizado y montaje de esas cuatro empresas de máquinas-herramienta permitió acceder a un trabajo de campo de terreno en que se reconstruyeron: a) las nuevas formas de diseñar los puestos de trabajo; b) los objetivos empresariales a cubrir con esos dispositivos de reorganización del trabajo; c) sus contenidos y resultados reales en las condiciones de trabajo, y d) las experiencias subjetivas de los actores sociales (organizadores de la producción y trabajadores) observados y entrevistados (Lahera Sánchez, 2000).
} 
bien a la primera y deseo de optar a una mejor calidad de vida laboral» (Senlle y Stoll, 1995: 88).

Para las gerencias y las ingenierías de producción de las empresas fabricantes de máquinas-herramienta analizadas, la calidad supone que, una vez diseñado y definido el producto, su fabricación debe realizarse por los operadores directos de forma correcta en el primer momento, «bien a la primera»:

«Antes, si tú hacías dieciséis piezas del lote y una te salía mal, pues no pasaba nada porque se fabricaba contra almacén: esa pieza mala iba a chatarra y había otra en almacén; hoy en día, como los pedidos son contra orden [stock cero], pues pieza que nos viene, pieza que tiene orden de máquina y entonces lo que no vale es que se haga chatarra. Una pieza a chatarra hay que reponerla y ocasionas un retraso: que vaya a chatarra supone que hay que volver a fundir, volver a mecanizar, y te supone un retraso de dos meses. Esto te obliga a garantizar la calidad: nosotros tenemos solucionado que cuando terminamos una pieza la verificamos, hay una ficha de control y tenemos que verificar las tolerancias o las medidas más importantes que el cliente nos manda medir: medimos y si está bien adelante, y si no, se analiza el fallo que pueda ocasionar. Eso lo que nos hace es garantizar que al cliente le va la pieza bien. Para garantizar esto, estamos intentando implantar ahora un sistema de autocontrol que nos permita garantizar durante el proceso que esa pieza se va a hacer bien» (director de Mecanizados, empresa Buruzagi).

Es el propio operador el que «produce la calidad». El trabajador debe conocer las especificaciones de calidad, detectar defectos en su propia actividad, corregir inmediatamente esos «errores», responsabilizándose de su eliminación, con lo que al final de su jornada pueda «asegurar» (hacerse personalmente responsable; Clutterbuck, 1994) que las piezas o montajes producidos cumplen lo demandado por la empresa sin necesidad de revisarlo: la justificación última de esta «participación para la calidad» es que «la suma de no-calidades acumuladas durante el desarrollo del proceso aumentan su coste final. Sabiendo que la definición útil de la no-calidad es aquella que la iguala con las cosas que tienen que repetirse por no haber resultado correctas a la primera, es fácil colegir que, si eliminamos las causas que originan errores, defectos y desperdicios, habremos disminuido costes y aumentado la calidad y rentabilidad de nuestra actividad» (Senlle y Stoll, 1995: 29).

Puesto que la calidad es ahora una atribución a desempeñar por los operadores directos, se trata simultáneamente de la aceptación directiva de delegar competencias anteriormente atribuidas a otras instancias organizativas (supervisores, encargados, inspectores de calidad...) hacia el taller, es decir, incrementar la participación de los trabajadores (exclusiva- 
mente) en lo referido a la gestión autónoma de su puesto de trabajo4. Que el trabajador directo (de mecanizado y montaje) asuma ahora las funciones de verificación y control cualitativo de la producción implica la definición gerencial de un nuevo contenido en sus tareas: la calidad es un proceso basado en la mejora continua de los procedimientos mediante los cuales se fabrican las piezas, conjuntos y máquinas. Los operadores no sólo deben producir obteniendo los requisitos de calidad establecidos en el diseño y definición de producto, sino que deben comprometerse a aplicar su inteligencia (colectiva) de producción para crear o construir a través de esa autonomía «mejores» formas de fabricar sus productos (Kern y Schumann, 1988; Schumann, 1998 y 1999): sus conocimientos y saberes tácitos y empíricos, junto a su creatividad individual y colectiva, se interpretan o valoran (y valorizan en términos de rendimiento económico y trabajo efectivo) ahora gerencialmente como recurso productivo clave para asegurar esa calidad: «Significa estimular la creatividad y la participación; significa entusiasmar a quienes intervienen en la actividad, sea ésta del tipo que sea; significa, en suma, motivar a las personas para que pasen de meros ejecutores a protagonistas» (Senlle y Stoll, 1995: 29); es decir, potenciar y capacitar, mediante estas prácticas participativas de empowerment, que los trabajadores incorporen su inteligencia productiva al proceso mediante su implicación actitudinal y comportamental a favor de la empresa (Cunningham, Hyman y Baldry, 1996: 145): explotando a favor de la gerencia yacimientos de capacidades y conocimientos ocultos que le habían resultado históricamente (y conflictivamente) inaccesibles (Pickard, 1994: 60), liberando así las energías creativas e innovadoras de los trabajadores para la supervivencia de la organización ${ }^{5}$ (Blanchard, Carlos y Randolph, 1996: 9; Hardy y Leiba-O’Sullivan, 1998: 452).

Frente al taylorista "one best way» o procedimiento óptimo (Taylor, 1914, 1925 y 1970), las empresas fabricantes de máquinas-herramienta estudiadas adoptan la característica de los principios de la producción ligera en el sentido de afirmar que la optimización o racionalización del proceso de fabricación no tiene fin y que debe lograrse de manera que los trabajadores «inventen» continuamente nuevos procedimientos de producción que permitan reducir el tiempo de trabajo y sus costes asociados, aumentar la calidad de las propias características del producto6 ${ }^{6}$ (Womack, Jones y Roos, 1991; Bonazzi, 1993). Por todo ello, la responsabilidad y el autocontrol significa que el operador en todo momento debe tener una

\footnotetext{
4 El debate teórico, académico y empresarial sobre el grado de «democratización» que puede incorporar el significado real del concepto «participación» se rastrea en Lahera Sánchez (2004), presentándose una metodología de evaluación crítica de la gestión participativa de los recursos humanos en empresas y centros productivos.

5 Este paradigma o interpretación gerencial sobre la calidad supone que «todo el personal debe participar en el proyecto, comprometiéndose con él como forma de asegurar el futuro» (Senlle y Stoll, 1995).

6 «No deberíamos renunciar al aporte de ninguna idea, opinión o sugerencia que pudiese favorecer la obtención de un instrumento más eficiente y que sea fundamentalmente asumido como propio por un número amplio de personas que estarán más predispuestas a su aplicación» (Senlle y Stoll, 1995: 81).
} 
actitud de búsqueda de mejoras y de soluciones en la actividad que realiza, debiendo configurarse como un solucionador cualificado de problemas a través de su participación e implicación: «Una empresa que desee implantar un sistema de calidad debe partir de la base que la implicación de los trabajadores es fundamental tanto para la implantación como para la mejora del sistema (...). De lo contrario, se creará una imagen entre los trabajadores de sentirse al margen del proceso y se desaprovechará la oportunidad para incluir sus propuestas durante la implantación» (Badia, 1998: 225).

Sin embargo, lo que se pretende destacar en nuestra interpretación es que, en términos de definición del proceso productivo, esta búsqueda de la calidad supone actuar empresarialmente en las formas de organizar el trabajo humano y en la manera de construir el vínculo social entre capital y trabajo que constituye las relaciones industriales de la empresa ${ }^{7}$ : la propia consecución de una producción de calidad se basa en construir gerencialmente y socializar entre los trabajadores una nueva cultura organizativa (o cultura de la empresa), es decir, un conjunto de valores y creencias compartidos que orienten los comportamientos de los propios trabajadores para que realicen correctamente sus tareas y sean simultáneamente creativos en sus puestos de trabajo, asegurando así la consecución de los objetivos empresariales, que deben interiorizarse como comunes y compartidos por parte de la fuerza de trabajo (Peters y Waterman, 1982), lo que requerirá un cambio en su actitud, su mayor motivación e involucramiento como claves «morales» de esta participación ${ }^{8}$ (Pickard, 1994):

"Aquí, a nivel máquinas, el salto cualitativo que se ha dado ha sido vía calidad. $A$ través de la calidad se están traccionando todos los cambios organizativos, de gestión e incluso filosóficos que se están dando en la empresa» (Director de Formación, Instituto de Máquina-Herramienta) ${ }^{9}$.

\footnotetext{
7 De hecho, las políticas de aseguramiento de la calidad tienen su origen en el conflicto industrial entre capital y trabajo, en la necesidad de garantizar que el trabajo humano salarizado fabrica calidad en productos que no son de su propiedad, que se autonomizan de su actividad como productor (en relación a su alienación capitalista respecto a los resultados de su trabajo [el fetichismo de la mercancía en Marx, 1979] ): «La búsqueda de la calidad en los productos ha existido siempre. Anteriormente era el propio artesano el que examinaba una por una todas las piezas que había realizado. Sin embargo, con Adam Smith y la aplicación de las teorías de la división del trabajo, los productos dejaron de ser producidos por un solo artesano para pasar a ser realizados por muchos operarios cada uno con una tarea muy concreta a realizar. Esta simple realidad, la división del trabajo, provocó que la calidad del producto no estuviera garantizada porque los productos habían pasado por muchas personas y ninguna de ellas se dedicaba a revisar el trabajo de las demás (...). Hasta entonces, el propio artesano garantizaba la calidad de sus productos porque en ello le iba el dinero con el que comer. Desde entonces, las empresas tendrán que buscar fórmulas para garantizar que la calidad del producto sea la adecuada ya que la motivación hacia la calidad de los empleados de una empresa no se puede comparar a la del artesano" (Badia y Bellido, 1999, 14; cursiva, ALS).
}

8 Por otro lado, los defensores y divulgadores de esta participación o empowerment nunca relacionan la motivación con una modificación de la retribución salarial del trabajador, sino que consideran que la recompensa y el orgullo de tener mayor responsabilidad provoca una más que suficiente satisfacción (Pickard, 1994: 59; Cunningham, Hyman y Baldry, 1996: 150).

9 El Instituto de la Máquina-Herramienta (IMH) de Elgoibar (Guipúzcoa) es el centro de formación profesional más relevante del sector, donde se intentan articular los conocimientos y cualificaciones a desempeñar por los alumnos como futuros traba- 
Por tanto, esta definición gerencial de la «participación» no es sólo una herramienta o técnica productiva, sino también un dispositivo para la construcción de orden en la empresa, de integración del trabajo humano como actor industrial y de acuñación de comportamientos «armoniosos» de los operadores (Castillo Mendoza, 1991; Lahera Sánchez, 2000b). Se trata así de crear una nueva «cultura organizativa de la calidad» mediante la aceptación por parte de los trabajadores u operadores de su necesaria implicación en la producción de la calidad, debiendo compartir con la gerencia los propios valores y comportamientos asociados a ella: mediante esta potenciación participativa (empowerment) de la (auto)responsabilización del trabajador se lograría contar con su experiencias, con sus capacidades y conocimientos, pero sobre todo, desde el punto de vista gerencial, con su compromiso en una supuesta mutualidad de intereses (Ogbonna, 1992: 79; Moraleda, 1997: 20; Kochan y Dyer, 1995: 334).

Esta apuesta managerial por la construcción de una "cultura organizativa de la calidad» (y, como se verá a continuación, por la fabricación de «trabajadores de calidad») afirma así, como justificación de la implantación de estas políticas participativas de gestión de la calidad, que éstas «no sólo son rentables en términos de aumento de la motivación del personal y de la comunicación entre los diferentes estamentos de la empresa, sino también como fuentes de ideas y propuestas de mejora de la calidad de la empresa, pues son estos trabajadores los que tienen un contacto más cercano con la actividad diaria y los procesos de la empresa» (Badia, 1998: 229), conformando e implantando así una perspectiva integradora sobre la «participación» como concepto productivo, es decir, como una técnica de gestión de los recursos humanos que facilita la integración de los trabajadores en los intereses empresariales de los organizadores de la producción (gerentes, directores, ingenierías...) (Lahera Sánchez, 2001: 76-83). Todo lo cual pretende, por parte de la gerencia, la implantación de una cultura organizativa «fuerte» (una cultura de empresa «vigorosa» ${ }^{10}$ ), es decir, lograr la adhesión generalizada e intensamente compartida en la empresa a un conjunto de valores, creencias y presunciones sobre cómo debe actuar la empresa y cómo deben comportarse sus integrantes (organizadores de la producción y trabajadores) (Deal y Kennedy, 1986; Schein, 1985; Killman, Saxton y Serpa, 1985; Infestas, 1991; Ouchi, 1982).

De hecho, la fabricación de esta «cultura vigorosa» de la calidad busca que «los trabajadores, mediante una cuidada selección e intensiva socialización, se comprometan con los va-

jadores a las necesidades de las empresas fabricantes de máquinas-herramienta. Esta institución formativa, creada en 1992, es una fundación formada por el Gobierno Vasco, la Diputación Foral de Guipúzcoa, el Ayuntamiento de Elgoibar, las asociaciones de empresarios (AFM y ADEGI), así como por los sindicatos más representativos a nivel de Euskadi (ELA-STV, CC.OO. y UGT), contando entre sus miembros con alrededor de noventa empresas del sector para las que el IMH diseña e imparte su formación.

10 «Una cultura vigorosa permite que el personal se sienta mejor con respecto a lo que hace, de modo que es más probable que trabaje más» (Deal y Kennedy, 1986: 17). 
lores que conducen la estrategia de negocio» (Legge, 1995), potenciando así una alta motivación en su actividad productiva en una especie de «contrato moral» en el interior de la empresa que permita "ganar los corazones y las mentes de los trabajadores» para los intereses de la gerencia (Guest, 1995: 113). De ahí la noción de la participación y de la delegación de la capacidad de toma de decisiones como compromiso organizativo mutuo (empowerment as a mutual commitment, Cunningham, Hyman y Baldry, 1996: 144), como interiorización por parte de los trabajadores de esa cultura empresarial en que deben comportarse "como si fueran propietarios de la empresa» (Blanchard, Carlos y Randolph, 1996) y entregando todos sus esfuerzos a su éxito. Se trata así de fabricar sujetos que se sientan altamente valorados, más entusiasmados y apasionados en su trabajo (Hardy y Leiba-O'Sullivan, 1998); todo ello mediante una especie de moral o ideología de servicio respecto a la «misión» mercantil de la empresa y su continua perfectibilidad (Elmes y Smith, 2001: 35), que acaba modelando el discurso gerencial de la participación como una nueva forma de persuadir a los trabajadores, a través de la delegación de responsabilidades, a cooperar con la autoridad gerencial (Edwards y Collinson, 2002: 277; Potterfield, 1999; Blyton y Turnbull, 1992).

Puesto que los intereses principales de las empresas son la supervivencia en el mercado a través del incremento de la productividad, la reducción de costes y la maximización del trabajo efectivo en la utilización de la fuerza de trabajo, es necesario vincular (integrar) precisamente a los operadores con esos intereses, siendo el reconocimiento de su participación en la gestión autónoma de su puesto de trabajo y su potenciación como decisores, en este caso en el aseguramiento de la calidad, el medio de identificar a los agentes empresariales antes enfrentados (al haber estado tradicionalmente sustentado su vínculo social en una cultura empresarial débil favorecedora del conflicto, según la perspectiva de los gurús del management; Willmott, 2001). La participación se construye gerencialmente así como una herramienta con la que obtener un «sentimiento de vinculación empresarial» entre capital y trabajo humano (Strauss y Rosenstein, 1970: 187-213; Tuckman, 1995: 54), que implique a los trabajadores en los cambios o transformaciones productivos de manera que se persuada a los trabajadores para conseguir su apoyo y no su resistencia (Ramsay, 1977; Cole, 1985: 569). Se diseña e implanta gerencialmente una ingeniería cultural (Kunda, 1992) que persigue cambiar sus actitudes «positivamente» a favor de la empresa, de los objetivos empresariales. El nuevo consenso industrial basado en los valores asociados a la cultura organizativa de la calidad tratará, por tanto, desde el punto de vista empresarial, de superar el tradicional e histórico enfrentamiento entre capital y trabajo (cultura de la empresa «débil») por una lógica de colaboración mutua (cultura organizativa «fuerte») (Bonavia y Quintanilla, 1999).

Comienza a hacerse así evidente el carácter disciplinario de la calidad como dispositivo de acuñación de comportamientos en los trabajadores que reduzcan el conflicto industrial: la 
calidad y la mejora continua requieren que el trabajador esté dispuesto a poner en juego sus conocimientos y creatividad a favor de la empresa, lo que depende de lograr su implicación positiva (a favor de los objetivos gerenciales) en la producción (Badia, 1998: 94) ${ }^{11}$. Todo ello permitirá contar con «personal más preparado; personal más implicado con los proyectos de calidad y menos reticente a los cambios; personal más flexible; personal más afín a la empresa; personal más productivo; personal más feliz (sic)» (Badia y Bellido, 1999: 85; cursiva, ALS) ${ }^{12}$; en definitiva, más adepto a la empresa (Castillo, 1998). De esta forma, a la cualificación de los operadores se ha añadido, desde el punto de vista de las exigencias gerenciales, el énfasis en una nueva dimensión de la cualificación referida a que los trabajadores adquieran y practiquen determinados comportamientos actitudinales considerados positivos por la empresa a través de la propia definición de esa «cultura organizativa de la calidad", que deben compartir los trabajadores y a la que deben adherirse lealmente («devotamente», Tuckman, 1995; en una «fe mutua», Ouchi, 1982: 84-85), garantizando que hacen lo correcto en beneficio de la empresa, «en beneficio de todos», sin tener en cuenta la posibilidad de la existencia de intereses colectivos o individuales conflictivos (Willmot, 2001; Meek, 1988). Son así socializados gerencialmente en «el modo correcto de percibir, pensar y sentir los problemas» (Schein, 1985: 26). De esta forma, el principal objetivo de las prácticas participativas o de empowerment sobre las que se construye la nueva cultura de la calidad es incrementar el compromiso de los trabajadores con la mejora de su trabajo y con su empresa para facilitar su flexibilidad (Cunningham, Hyman y Baldry, 1996: 143), acuñando así trabajadores con un «espíritu de mejora» (betterment spirit worker, Edwards, 1979: 94):

«Hoy en día, un discurso que amenaza con ser dominante en poco tiempo, presenta la implicación, el involvement, como un rasgo necesario de la cualificación de los trabajadores (...) Un rasgo organizativo y actitudinal se eleva a categoría cualificacional: así, trabajadores cualificados serán aquellos confiados, implicados o integrados en los valores empresariales» (Castillo, 1997: 93).

\footnotetext{
11 Esta concepción sobre la calidad y la mejora continuas de procesos y productos implica realmente una redistribución de la intensificación y explotación de la fuerza de trabajo: obtener en un mismo periodo de tiempo de explotación del trabajo humano mayor trabajo efectivo a través de la saturación de la actividad de los operadores mediante el incremento de las tareas y funciones que tienen que desempeñar. En otras palabras, el trabajo indirecto (en este caso el control de calidad) no desaparece, sino que se "sobrecarga" en las tareas directas, incrementando su intensificación: no es que la antigua mano de obra indirecta sea innecesaria y por eso tienda a desaparecer, sino que se la hace innecesaria porque se transfiere su (carga de) trabajo a la mano de obra directa como gestora, en este caso, de la calidad (Castillo, 1996 y 1998). Desde esta perspectiva, la participación o las prácticas de empowerment «se configuran como un eufemismo de la intensificación del trabajo» (Hyman y Mason, 1995: 387)

12 «En este sentido, los superiores deben saber delegar y dar responsabilidad a sus subordinados a la vez que controlan los resultados y los apoyan con su formación. Es muy importante la confianza en los subordinados y el dar libertad de movimientos para que éstos se sientan motivados a hacer las cosas bien y en mejorarlas si es posible (...). Los resultados deben buscarse por medio de la comunicación y la discusión, nunca por medio de las órdenes y las reprimendas» (Badia y Bellido, 1999: 47.
} 
Si tradicionalmente la cualificación se refería fundamentalmente al saber-hacer del trabajador, esta cualificación actitudinal se refiere al saber-ser o saber-estar, donde lo que se valora empresarialmente es la responsabilidad, la iniciativa, la postura cooperativa, la implicación o el compromiso con los objetivos gerenciales (Leite, 1999). Se relaciona así la calidad y la mejora continuas con la inversión en la construcción de nuevas actitudes comportamentales de los trabajadores mediante una formación actitudinal que permita crear, o fabricar «moralmente», un trabajador «motivado, cooperador, sensibilizado, cuyas actitudes positivas ayuden» a mantener la empresa (Senlle y Stoll, 1995: 38), a través de su internalización de los nuevos valores organizativos de la calidad y la implicación (una nueva «personalidad corporativa»; Ouchi, 1982: 130): “La filosofía de la empresa se resume en la calidad. La calidad se convierte por esta vía no sólo en una nueva forma de producir, sino en un estilo de convivir, de colaborar, de actuar (...). El compromiso moral de todos los que participan en la fabricación de un bien o en la prestación de un servicio» (Sarriés, 1994: 53-55; cursivas, ALS). El problema gerencial del aseguramiento de la calidad total se sitúa así enfáticamente en la necesidad de transformar los valores y actitudes de los trabajadores hacia la nueva cultura organizativa de la calidad (Willmott, 2001: 391) ${ }^{13}$, lo que permitirá crear consenso (una cultura de empresa fuerte), predecir y controlar los comportamientos de los trabajadores y crear unidad en la organización (Meek, 1988: 363-369).

El objetivo último de esta participación en la calidad es, por tanto, la acuñación en los operadores de una «implicación entusiasta» (enthusiastic involvement) en los objetivos empresariales (Graham, 1995: 95), de manera que no sea necesaria una supervisión detallada de su actividad: el operador se autocontrola, se autodisciplina y vigila al comprometerse a trabajar correctamente desde el principio, como si, desde una perspectiva crítica, en el fondo disfrutara de su explotación (Hardy y Leiba-O'Sullivan, 1998: 467): «al abrazar esta nueva forma disciplinaria de autogestión individual para lograr los fines organizativos, los trabajadores se convierten en participantes de la colonización de otro aspecto de su dimensión afectiva, en este caso, de sus almas» (Elmes y Smith, 2001: 37).

Se trata así de fabricar gerencialmente un trabajador que transforme también sus caracteres «morales» (Martín Criado e Izquierdo, 1993), mediante «un cambio en el tipo de persona que debe trabajar en la fábrica» (Miller y O'Leary, 1994). Tan sólo se puede hablar gerencialmente de participación en cuanto a que los operadores, la fuerza de trabajo, debe implicarse mediante el desarrollo de una nueva actitud hacia su trabajo, hacia el proceso productivo y hacia la empresa (respecto al capital). Se intenta fabricar gerencialmente trabajadores de calidad, que realicen una actividad de calidad, que la mejoren continuamen-

13 «Los empleados simplemente trabajan un poco más porque están dedicados a la causa» (Deal y Kennedy, 1986: 35), logrando que sean más productivos y «entregados al trabajo» (Ouchi, 1982: 86) a través de la lealtad, identificando sus logros personales con los de la empresa. 
te, que satisfagan las demandas cualitativas de los clientes y que mantengan a la empresa en beneficios (Roberts y Corcoran-Nantes, 1995: 99). De ahí que en el fenómeno del aseguramiento y certificación de la calidad se incorporen esos contenidos integradores sobre los que estas empresas persiguen la construcción de un nuevo orden productivo que permita incrementar la legitimación de la disciplina de producción y obtener el control empresarial sobre el trabajo humano mediante dispositivos participativos que le aseguren también la lealtad de los propios trabajadores (Fantasia, Clawson y Graham, 1988; Lahera Sánchez, 2000b; Willmott, 2001: 391). «Participación» que es interpretada gerencialmente en el sentido de que los trabajadores deben hacerse partícipes e implicarse en los nuevos valores y normas de esa nueva cultura organizativa de la calidad, hacerse partícipes de los objetivos empresariales mediante su aceptación y afirmando la voluntad de actuar para su consecución (Infestas, 1991: 159): debe construirse la calidad en la conciencia de cada trabajador $^{14}$ (Willmott, 2001: 416):

"Los empresarios se han lanzado a lo que he llamado una batalla de identidad consistente en modernizar la mente de los asalariados, es decir, conseguir que éstos interioricen los valores y la cultura de la empresa, adopten sistemáticamente métodos estándar de razonamiento, en "formatearles" una mente gestora y empresarial, eso sí, en el modo de la "one best way" empresarial, es decir, partiendo de la racionalidad dominante de la empresa que excluye cualquier tipo de debate, cualquier discusión posible, cualquier propuesta alternativa respecto del modo de gestión. Se trata de obligarles a renunciar a la solidaridad de la profesión, de la clase, para adoptar únicamente los valores de la empresa» (Linhart, 1997b: 31).

\section{LA CALIDAD COMO NUEVO DISPOSITIVO DISCIPLINARIO: DE LA PROCEDIMENTALIZACIÓN DE LOS PROCESOS}

\section{A LA TRAZABILIDAD DE LOS SUJETOS}

Durante los años noventa, las empresas fabricantes de máquinas-herramienta consideradas en esta investigación vincularon sus nuevas estrategias productivas a la consecución de mayores niveles de calidad. Para ello recurrieron, como gran número de empresas es-

\footnotetext{
14 Participación y formación en actitudes tales como «la tenacidad, el afán de superación, la actitud agresiva frente a los problemas» (Senlle y Stoll, 1995: 76) que conforman el modelado del tipo de trabajador de calidad definido y deseado gerencialmente: que no considere sus intereses enfrentados a los de los organizadores de la producción, sino, por el contrario, similares y convergentes («todos vamos en el mismo barco»). Es interesante destacar cómo este significado actitudinal de la perspectiva gerencial sobre el concepto «participación» se aleja de la tradicional demanda sindical de mayor participación de los trabajadores en términos de incremento de su cualificación (tareas de mayores conocimientos y pericias) y de autonomía o soberanía productiva sobre la gestión de su actividad de trabajo (Kern y Schumann, 1988; Schumann, 1998 y 1999 ; Reygadas, 2002: 274-279).
} 
pañolas en estos años, a desarrollar planes de aseguramiento de la calidad conforme a la familia de normas estándares internacionales ISO-9000 ${ }^{15}$, que les permitieran certificar hacia el exterior que realizan sus producciones con una alta calidad en cada una de las fases del proceso de trabajo, todo ello como apuesta para gestionar las nuevas características de la incertidumbre del mercado:

«Los empresarios que no tengan preparación específica en todas estas disciplinas no tienen futuro, como tampoco lo tienen sus empresas (...) Si las empresas van bien, son rentables y funcionan con una aceptable calidad integral en toda su gestión, aseguran su futuro, garantizan nuevos puestos de trabajo, mueven la economía, dinamizan el mercado y ayudan a desarrollar la región y el país (...). La toma de conciencia se generaliza y la salida está clara, todo empresario quiere garantizar su futuro, ahorrar gastos, ser competitivo y pretende tener como proveedores a otros empresarios que garanticen su calidad de producto y servicio, que le ahorren gastos, que le eviten hacer controles, plantear constantes quejas, le resuelvan problemas o le abaraten costos (...). Quien no esté en un proceso de normalizar su empresa, implantar un sistema de calidad y obtener la certificación NO TIENE FUTU$R O »$ (Senlle y Stoll, 1995: 50-51; mayúsculas en el original).

\subsection{Racionalización y normalización del proceso de trabajo: el Sistema de Normas de Calidad ISO-9000}

La normativa ISO- $9000^{16}$ pretende «asegurar y optimizar la calidad en la gestión de una organización para satisfacer los requerimientos y necesidades de los clientes, así como generar confianza y seguridad» (Badia, 1998: 122), es decir, su finalidad es la de establecer los requisitos de un sistema de gestión de calidad para demostrar la capacidad de una empresa para diseñar y suministrar un producto conforme a las demandas del cliente ${ }^{17}$. Supone establecer un conjunto de reglas fijadas y formalizadas que implican y coordinan toda la

15 En concreto, estas empresas poseen la certificación de la norma ISO-9001, referida al aseguramiento completo de la calidad en el diseño, el desarrollo, la producción, la instalación y el servicio posventa de un producto (Normas ISO-9000, AENOR, 1994: introducción).

16 El conjunto de normas ISO-9000 son emitidas por la International Standard Organization (ISO), como organismo que agrupa a los diferentes organismos nacionales de normalización; el Comité Europeo de Normalización las asume como Normas Europeas (European Norms-EN), y a nivel local la Administración española las asimila como Una Norma Española (UNE) $(\mathrm{UNE}=\mathrm{EN}=\mathrm{ISO}-9000)$. En estos tres niveles, se trata de aplicar la perspectiva de «hacerlo una sola vez, hacerlo bien y hacerlo internacional» (Badia, 1998: 352-368).

17 La norma ISO-9000 define el «sistema de calidad» como el «conjunto de estructura de la organización, de responsabilidades, de procedimientos, de procesos y de recursos que se establecen para llevar a cabo la gestión de la calidad» (AENOR, 1994). 
actividad desempeñada por la empresa que puede incidir en su capacidad para asegurar la calidad del producto como base para obtener la confianza de los potenciales clientes (OMPES, 1998: 11). Implica considerar que la implantación de un «sistema de aseguramiento de la calidad» proporciona a la empresa mejoras organizativas que le permitirán su supervivencia:

«Desde el punto de vista comercial: facilita la penetración en los mercados extranjeros, mejora la relación calidad-precio como consecuencia de la eliminación de los costes de la no-calidad, y mejora la relación con el cliente; desde el punto de vista financiero: mejora la gestión y optimización de los recursos, reduce los costes de la no-calidad haciendo bien las cosas a la primera (...); desde el punto de vista interno: fomenta la implicación del personal en los objetivos de la organización, el trabajo en equipo y la definición de las responsabilidades individuales (...); mejora la credibilidad técnica de la empresa y supone un argumento comercial eficaz» (Badia, 1998: 65).

Ahora bien, si, en términos comerciales, la implantación de esta normativa implica supuestamente dotar a la empresa de una estructura que facilita su respuesta a las exigencias del mercado y de una serie de técnicas para el control, la evaluación, la procedimentalización y la corrección del proceso de trabajo, en términos productivos, esta familia de normas ISO9000 supone un nuevo dispositivo de racionalización de la producción (Segrestin, 1997), lo que es fundamental para entender sus efectos sobre las condiciones de trabajo de los operadores, como se analizará en breve:

"Si mejoramos la calidad de un proceso productivo, reducimos los reprocesos, las repeticiones de los productos que han salido mal. Si conseguimos reducir el tiempo dedicado a repetir los productos mal hechos, seguro que aumentaremos la productividad porque dedicaremos más tiempo a producir productos buenos. Este aumento de la productividad supone una reducción de los costes del producto pues con el mismo nivel de costes conseguimos un mayor número de productos sin defectos. Estos dos factores, la reducción del coste y la reducción de los productos defectuosos, provocarán un incremento de la satisfacción de los clientes, ya que le ofrecemos un producto más fiable y probablemente a un menor precio. La satisfacción del cliente asegurará la continuidad en el negocio y la obtención de mayores beneficios de manera progresiva» (Badia y Bellido, 1999: 25).

Esta racionalización se desarrolla debido a que las normas ISO-9000 establecen una serie de requisitos y prescripciones que es necesario cumplir para asegurar la calidad, debiendo la empresa diseñar procedimientos de actuación para resolver cada una de esas exigen- 
cias de la norma (procedimientos que deben quedar definidos y recogidos por escrito). En general, en estos procedimientos se formalizan y definen las normas, las responsabilidades, el ámbito de aplicación y los objetivos de cada uno de los departamentos y puestos de trabajo en lo referente a cómo conseguir la calidad, definiendo paso a paso cómo llevar a cabo una actividad ${ }^{18}$ al describir qué hacer, cómo hacerlo, cuándo hacerlo, cuánto hacer, dónde y quién debe realizarlo (Badia, 1998: 209; Senlle y Stoll, 1995: 82):

"Un procedimiento es un documento que describe clara e inconfundiblemente los pasos consecutivos para iniciar, desarrollar y concluir una actividad u operación relacionada con el proceso productivo o de suministro de servicios, los elementos técnicos a emplear, las condiciones requeridas, los alcances y limitaciones fijados, el número y características del personal que interviene. Debe incluir, ineludiblemente, datos precisos sobre las personas que se responsabilizan de los resultados a obtener y su posible delegación» (Senlle y Stoll, 1995).

Esta exhaustiva formalización establecida por las normas ISO-9000 implica el desarrollo por parte de estas empresas de nuevas normas para el control de los procesos de trabajo y producción, mediante la construcción y diseño gerencial de instrucciones de trabajo en que se describen las maneras pertinentes y permitidas de realizar una operación, las órdenes a seguir por los operadores y sus criterios de aplicación, que deben ser cumplidos tal y como se establecen en los procedimientos de actuación (Badia, 1998: 131): describen y establecen documentalmente los contenidos de las operaciones que tienen que realizar en cada punto del proceso de producción y en cada puesto de trabajo los operadores para que el proceso se ejecute correctamente (qué se debe realizar y cómo se debe realizar).

\subsection{La construcción de un nuevo taylorismo a través de la participación de los trabajadores en el aseguramiento de la calidad}

Teniendo en cuenta este origen normalizador y racionalizador, lo fundamental en términos de organización del trabajo realmente existente, es decir, en las situaciones reales de trabajo (Castillo, 1997), es que las políticas de aseguramiento de la calidad implantadas por las empresas fabricantes de máquinas-herramienta analizadas en el trabajo de campo de esta investigación se basan, como se ha ido señalando a lo largo del epígrafe, en la imprescindible (tal y como lo establecen las normas ISO-9000 tomadas como criterio) acentuación de la procedimentalización del proceso productivo y estandarización de las tareas de los operadores: éstos deben realizar sus tareas y funciones siguiendo detalladamente

\footnotetext{
18 De hecho, la normalización o establecimiento de una norma supone un conjunto de «reglas que se deben seguir o a las
} que se deben ajustar las operaciones» (Senlle y Stoll, 1995: 30), ése es el significado de las propias «normas» ISO-9000. 
(«al pie de la letra»; director de Recursos Humanos, empresa Buruzagi) las instrucciones de trabajo mediante las que se definen los contenidos de las fases consecutivas del proceso y los criterios de calidad a seguir:

«Todas las empresas que han hecho un plan de calidad se han visto obligadas a definir claramente las funciones y las responsabilidades de cada puesto: para hacer todo esto, tiene que estar procedimentalizado; los planes de calidad han obligado a que se procedimentalicen los trabajos, las funciones; en función de esos procedimientos se ha definido cada vez más en fino, cómo tiene que ejecutar el trabajo ese operario. Antes todo era oral, pero hoy en día se está tendiendo cada vez más, vía el método, a que todo quede procedimentalizado y al operario se le puede exigir responsabilidad porque se le está diciendo realmente cómo tiene que hacer las cosas» (técnico de Formación en I+D, Instituto de Máquina-Herramienta).

«Tú tienes un procedimiento y hay que aplicar los procedimientos de trabajo. $Y$ el tema de entrar en normas [de calidad] te marca eso» (director de Mecanizados, empresa Berritzaile).

Por todo ello, se comprobó en los talleres de mecanizado y montaje de las empresas Buruzagi, Zuzendu y Beritzaile que la implantación de la calidad total origina una reactualización de la estricta división entre concepción y ejecución taylorista, puesto que son la gerencia y la ingeniería de producción las que definen detalladamente, por escrito y documentalmente, las tareas y los procedimientos que deben seguir obligatoriamente los trabajadores para conseguir los criterios de calidad, también construidos y establecidos «monopólicamente» por la gerencia, a cumplir por las máquinas-herramienta fabricadas (Taylor, 1914, 1925 y 1970). El objetivo normativizador del aseguramiento de la calidad se centra en «desarrollar estándares y procedimientos en todas las tareas y actividades relacionadas con el proceso y debe asegurarse que todo el personal que participa en el proceso comprende y emplea los estándares y procedimientos establecidos» (Badia, 1998: 113). De esta forma, los trabajadores tan sólo deben seguir esas instrucciones para realizar su actividad (Hardy y Leiba-O'Sullivan, 1998: 463-464), sobre todo teniendo en cuenta que la propia procedimentalización debe permitir que cualquier operador aprenda rápidamente cómo realizar ese puesto de trabajo, lo que incide en facilitar la transferencia flexible de un operador de un puesto a otro, pero simultáneamente la prescindibilidad de cada trabajador individualmente considerado ${ }^{19}$, homogeneizándose la (des)cualificación del obrero colecti-

19 Precisamente, la formalización reflejada en la documentación permite a las empresas conservar sus conocimientos y experiencias acumulados más allá de la memoria de los individuos, debiendo permitir que un operador novato en ese puesto o actividad, tan sólo leyendo y siguiendo la instrucción de trabajo, pueda realizar esa actividad de manera correcta y conforme en términos de calidad, independientemente de su experiencia. 
vo: «todos son intercambiables y ninguno insustituible» (Delbridge, Turnbull y Wilkinson, 1992: 101):

«Información transparente, asociativa y que no dependa de la persona, porque, si te falla la persona, no encuentras esa información. Lo que no queremos es depender de la persona. Reingeniería de procesos: reformar procesos y procedimentalizar» (director de Calidad e I+D, empresa Buruzagi).

"Con eso lo que ganamos es que no haya imprescindibles y que ese conocimiento, que está en el taller, el día de mañana cuando ése esté de baja venga otro y lo haga igual porque tiene ese conocimiento escrito ahí y la referencia de qué es lo que hay que hacer. Al final es que ese conocimiento que está por ahí, que existe, ser capaces de pasarlo a papel y quede donde tiene que quedar, las polivalencias serían más posibles, a la gente le costaría menos adaptarse a las máquinas y a los procedimientos» (director de Mecanizado, empresa Buruzagi).

Ahora bien, la procedimentalización da lugar también a una técnica de extracción y transferencia de conocimientos productivos desde el taller a la dirección y su ingenería de producción, precisamente a través de esta alternativa de participación o empowerment de los trabajadores en las decisiones sobre la calidad diseñada gerencialmente. Como se señaló anteriormente, la dirección de las empresas delegan o abren la participación de los trabajadores para que éstos se involucren movilizando su inteligencia productiva en obtener la mejora continua de los procedimientos de trabajo a desempeñar en sus puestos. Es en esta perspectiva sobre la consecución de la calidad a través de la facilitación de la autonomía de los operadores para que optimicen continuamente y sin descanso los resultados de su actividad (la difundida internacionalmente e intensificadora «tensión creadora» de la producción ligera; Castillo, 1998; Sandberg, 1995) donde se apoya la propia procedimentalización exhaustiva del proceso de trabajo y sus tareas, característica de estas políticas de aseguramiento de la calidad basadas en la familia de normas ISO-9000: una vez que los operadores construyen una «nueva mejor manera» de realizar sus tareas, deben transferirla a la propia documentación escrita y registral de las instrucciones de trabajo establecidas por el plan de calidad, con lo que esa inteligencia de producción poseída cultural y colectivamente por los trabajadores queda reificada o endurecida de forma externa y heterónoma al propio trabajador o trabajadores que la han ideado. Su inteligencia de producción, sus conocimientos y experiencias quedan capturados por los procedimientos de calidad, lo que permite precisamente extraer ese conocimiento y no necesitar ya al operador que lo ha creado, puesto que ahora cualquier otro operador puede aplicarlo de forma independiente tan sólo siguiendo ese procedimiento y esas instrucciones de trabajo que se autonomizan al margen del trabajador: 
«Es aprovechar el conocimiento del taller. Lo que está claro es que un joven se pone mucho más rápido en una máquina, pero no tiene el conocimiento de un veterano respecto a utillajes, herramientas y demás, pero si tú tienes el proceso por escrito y lo tienes bien documentado, cualquiera que venga, si tiene una mínima formación, sería capaz de interpretar eso que tienes por escrito y sería capaz de hacerlo bien, y cuanto más lo tengas soportado la información de ese proceso, mejor te lo va a hacer: reduciéndose drásticamente el periodo de formación al tener el conocimiento escrito» (director de Mecanizados, empresa Berritzaile).

«Nos obligó a montar un departamento de métodos de montaje, en los que se documentaron todas las pautas de montaje. Ir plasmando lo que estábamos viendo y lo que ellos te decían, tan sencillo como eso. Se trataba de trasladar los conocimientos de los más experimentados al papel para que todos puedan aprenderlos. La procedimentalización ha permitido dar base a los chavales: antes cuando venía un chaval nuevo lo ponías con uno que tenía experiencia e iba aprendiendo a medida que observaba y copiaba lo que el otro le iba soltando, y tardábamos un montón de años en que una persona arrancase. Ahora el proceso es a la inversa, les damos los conjuntos o subconjuntos, les ponemos con un veterano, pero de a poco ya le soltamos y tiene que ser capaz de montar la máquina entera siguiendo tan sólo los procedimientos» (director de Montaje, empresa Buruzagi).

De esta forma, el aseguramiento de la calidad desarrollado en estas empresas durante los años noventa implica que el reconocimiento gerencial de la autonomía de los trabajadores en su actividad, de la ampliación de su soberanía temporal y procedimental y de la movilización de su inteligencia de producción se diseñan gerencialmente como dispositivos de control del trabajo humano de carácter taylorista. Reproducción y (re)construcción de las prácticas y principios tayloristas en cuanto a que estas políticas de participación se orientan a la detallada procedimentalización de las tareas a desempeñar por los operadores, tareas que además están definidas nuevamente (lo que históricamente ha caracterizado tradicionalmente al taylorismo) por la oficina técnica o la ingeniería de producción, que, al definir el plan de aseguramiento de la calidad y las instrucciones de trabajo mediante las que diseña detalladamente la actividad de cada puesto, los métodos para desempeñarlas y las verificaciones a realizar obligatoriamente por los operadores, retiene la función de concepción del proceso de trabajo 20 :

"Se han elaborado y definido todos los procedimientos; más que elaborarlos, que eso no es tan complicado, el aseguramiento de su cumplimiento, que los operarios

20 «Instrucciones que se dan de forma precisa. Se redactan procedimientos y documentos para que las personas sepan claramente qué deben hacer y cómo. Los métodos de autocontrol se implantan para que ayuden a que las cosas se hagan bien a la primera» (Senlle y Stoll, 1995: 104). 
siguen sus instrucciones detalladamente» (director de Recursos Humanos, empresa Buruzagi).

«Los procedimientos de la realización del trabajo, por una parte, quedan escritos y, por otra parte, que también quede escrito, no sólo el proceso de realización de ese trabajo, sino los criterios que hay que tener a la hora de hacer ese trabajo, que es donde entra la concreción de la experiencia. Se trata de que la experiencia del personal quede reflejada en los criterios, queden reflejados todos los criterios de realización que se tienen que llevar a cabo durante la fabricación de una máquina» (director de Formación, Instituto de Máquina-Herramienta).

Sin embargo, el proceso de trabajo queda abierto a la participación de los trabajadores a nivel de sus puestos de trabajo (y exclusivamente a ese nivel, como se señalará posteriormente); de ahí que algunos autores hayan denominado a estas prácticas como taylorismo participativo o democrático (Adler y Cole, 1995; Jones, 1997), pudiendo decidir qué mejoras introducir para perfeccionar continuamente esas instrucciones de trabajo definidas gerencialmente, mejoras que, sin embargo, son aceptadas o rechazadas por la propia oficina técnica, que, a pesar de haber delegado la posibilidad de crear o perfeccionar sus métodos al taller, sigue controlando y limitando la supuesta idoneidad de los resultados de esa autonomía obrera a aquellos problemas productivos predefinidos por la propia gerencia, limitándose así la posibilidad de que los trabajadores cambien efectivamente las prescripciones establecidas en las instrucciones de trabajo (Hales, 2000: 506-509). Es así como estos dispositivos participativos en la delegación de la gestión de la calidad permiten a la gerencia la extracción y documentación del conocimiento del obrero colectivo, es decir, obtener un recurso productivo de racionalización que de otra forma, e históricamente, no habría podido movilizar:

«Tienen una total autonomía, sin cortapisa: tiene que ver cómo resolver el problema, si el procedimiento se puede mejorar, inventar cosas nuevas, incluso herramientas o lo que sea, mejorarlo para mejorar todos y la empresa. En cuanto se introduce alguna manera nueva, que sea válida, no cualquiera, se pone en el documento y, a partir de ahí, tienen que seguir las pautas de nuevo, si algo sucede y no puede avanzar tiene que indicarlo para revisar la causa y poner en marcha la forma de continuar, así de forma continua, sin parar. Los conocimientos de los veteranos no son ya tan necesarios, lo tengo clarísimo, porque ahora son de todos» (director de Montaje, empresa Buruzagi).

Por tanto, en términos de prácticas efectivas de organización del trabajo, los objetivos del aseguramiento de la calidad a través de este tipo de participación de los trabajadores im- 
plantada en estas empresas mediante la aplicación de las normas ISO-9000 han supuesto la construcción de una nueva técnica disciplinaria de control del trabajo y de los operadores (Badham y Jürgens, 1998: 42), en que se recupera la procedimentalización y estandarización taylorista de sus tareas y puestos de trabajo de manera combinada a la expropiación de sus conocimientos y experiencias, que, a través de la propia participación o implicación de los trabajadores en la cultura organizativa de la calidad («trabajadores de calidad»), quedan a disposición de la gerencia mediante su "captura» en documentos e instrucciones de trabajo que la permiten controlar de forma extremadamente precisa el propio proceso (Durand, 1998: 193), el cual además sigue siendo continuamente perfeccionado y procedimentalizado por la interiorización por parte de los operadores de la actitud hacia la mejora continua impuesta por la dirección (Conti y Warner, 1993): transfiriendo «participativamente» a través de la «mejora continua» su inteligencia de producción, de nuevo, del taller a la oficina. Mientras que el discurso empresarial enfatiza «la idea de una evolución más bien radical, las prácticas revelan, en la mayoría de los casos, una inercia en cuanto a los principios tayloristas fundamentales» (Linhart, 1997: 77). Se produce así la subcontratación de los ejecutantes para la realización de la «investigación empírica» que anteriormente era función de la oficina de métodos y procesos, lo que permite estandarizar continuamente los procedimientos o métodos de trabajo mediante las aportaciones del taIler (Graham, 1995: 113; Linhart, 1997: 39-40; Linhart, 1990; Paniagua López, 1999).

En definitiva, para la consecución de la nueva cultura empresarial de la calidad, las gerencias de estas empresas diseñan e implantan el sistema de normas ISO-9000 como un dispositivo (una tecnología política de control o ingeniería cultural) para la transformación de las actitudes, valores y prácticas de los trabajadores, que mediante su vinculación «moral» a los nuevos principios de gestión (la nueva «cultura organizativa de la calidad») incrementan su propia explotación (McArdle et al., 1995: 161; Burawoy, 1985; Willmot, 2001: 399)²1.

Al mismo tiempo, dentro de esta actualización gerencial de los principios y prácticas tayloristas incorporados en las políticas de participación en la calidad, es imprescindible enfatizar que el alcance o grado de intensidad de esa participación está fuertemente limitado por los propios organizadores de la producción de estas empresas (gerencias e ingenierías). Esa participación de los trabajadores no está abierta a materias estratégicas de decisión empresarial: diseño y definición de producto, políticas de inversión y de dividendos, procedimientos de contratación y retribuciones salariales, reducción de costes y presupuestos fi-

\footnotetext{
21 Sin embargo, a pesar de los intentos gerenciales, se siguen manteniendo fenómenos de resistencia por parte de los trabajadores, que subvierten la lógica disciplinaria de la implantación de las normas ISO-9000 de calidad (Schied, Carter, Preston y Howell, 1997), incluso diseñando procedimientos que no respetando lo establecido en las instrucciones de trabajo permiten mejorar el proceso productivo y su calidad, siendo ese conflicto (un juego de guerra entre taller y gerencia), paradójicamente, funcional para los intereses empresariales, tal y como ocurrió en las empresas vascas analizadas (Lahera Sánchez, 2000b).
} 
nancieros, diseño e introducción de nuevos equipamientos tecnológicos en el proceso de trabajo, propiedad y control sobre las empresas (Cressey y Di Martino, 1991: 174; Lahera Sánchez, 2001), materias que componen y han compuesto históricamente los ámbitos de decisión exclusivos del capital o de la dirección gerencial en su discrecionalidad organizativa para la determinación de los objetivos y medios globales o centrales de funcionamiento de la empresa (Wilkinson y Willmott, 1995: 4). Por el contrario, esa participación propiciada en la nueva cultura organizativa de la calidad se limita tan sólo a materias procedimentales exclusivamente referidas a los contenidos de las tareas y procedimientos de trabajo, a la gestión con mayor autonomía de su puesto de trabajo por parte de los operadores, como supondría la propia calidad, y sin posibilidad de que los propios trabajadores o sus representantes hayan podido intervenir en la definición y selección de las alternativas organizativas propuestas por la dirección en la reorganización del trabajo, o incluso contraargumentarlas (Lahera Sánchez, 2001 y 2003)²2.

Esta nueva cultura de la empresa basada en la calidad no trata así ni de avanzar en la democratización de las relaciones industriales ni tampoco fundamentalmente de humanizar las condiciones de trabajo de los operadores, sino de emplear la propia participación en el aseguramiento de la calidad como una nueva técnica gerencial al servicio de los objetivos e intereses de la dirección (Lahera Sánchez, 2004). Todo lo cual no implica en estas cuatro empresas, por tanto, un cambio trascendente de la forma en que construyen sus relaciones industriales, sino una actualización disciplinaria que, mediante la delegación de una parte muy limitada del poder organizativo en los trabajadores mediante su autonomía procedimental y el enriquecimiento del trabajo ${ }^{23}$, logra mantener el orden en la producción y reducir el conflicto industrial, sin un reequilibrio real del poder asimétrico entre ambos actores productivos (Fantasia, Clawson y Graham, 1988). Se trata fundamentalmente de generar realmente en los trabajadores una autonomía disciplinada con unas expectativas productivas claramente definidas y limitadas: «Los gerentes aman el empowerment [la participación; ALS] en teoría, pero el modelo de ordeno-ymando es en el que confían y el que mejor conocen» (Argyris, 1998: 98)24.

\footnotetext{
22 «Los trabajadores no son tratados como iguales, ni siquiera consultados cuando las empresas deciden adoptar programas de gestión de la calidad: a menudo tan sólo son entrenados en sus prácticas una vez que el programa ha sido adoptado por la gerencia» (Kerfoot y Knights, 1995: 230).

23 Se pueden evaluar así las políticas de participación de los trabajadores en estas empresas fabricantes de máquinas-herramienta como de baja intensidad, puesto que no suponen un avance significativo hacia la democratización de sus relaciones industriales, hacia una verdadera democracia industrial. La evaluación detallada del limitadísimo alcance democratizador de las políticas de gestión participativa de los recursos humanos en estas empresas se encuentra en Lahera Sánchez (2003).

24 Siguiendo a Potterfield, la distribución completamente equilibrada del poder de toma de decisiones entre trabajadores y gerencias nunca ocurre en el mundo del trabajo: los trabajadores, a pesar de la participación o del empowerment, nunca escapan de la servidumbre industrial del puesto de trabajo (Potterfield, 1999). De hecho, la ausencia de objetivos democratizadores en estas prácticas participativas por parte de las gerencias se enfatiza con la marginación sindical en su definición e implantación (Cunningham, Hyman y Baldry, 1996: 152).
} 


\subsection{La trazabilidad de la calidad como nuevo dispositivo de disciplina industrial}

Las políticas de aseguramiento de la calidad completan sus técnicas de detallada procedimentalización del proceso productivo con la implantación de otra técnica de fabricación de la calidad: la trazabilidad de los productos y de los procesos. Esta trazabilidad implica tener siempre y continuamente identificado el producto fabricado y sus componentes durante todo su proceso de producción, es decir, debe permitir seguir su itinerario desde que "entra» hasta que «sale» de la empresa, todo ello para poder también rastrear la aparición de errores o no conformidades en el producto respecto a los niveles de calidad y los procedimientos establecidos, así como detectar dónde y en qué momento del proceso se han producido, remontando todas las fases de fabricación hasta llegar a aquella donde se ha realizado alguna parte del procedimiento de forma no conforme a como establecen las instrucciones de trabajo. El objetivo final de la trazabilidad es que, una vez que se ha detectado el error, se pueden rastrear las razones por las que se ha originado y plantear las acciones correctoras o de mejora que eviten de forma preventiva su repetición. De hecho, esta técnica organizativa de la trazabilidad es una derivación de la propia lógica de la obtención y aseguramiento de la calidad total a través de la implicación en la mejora continua del trabajo humano, ya que se trata de que, una vez identificada una no conformidad y trazada dónde y cuándo se ha producido, los propios operadores deban analizar conjuntamente con la ingeniería de producción gerencial su origen y causas, así como crear nuevos métodos para corregir y evitar ese error, para lo que de nuevo las gerencias interpretan la pertinencia inexcusable de la inteligencia de producción de los trabajadores, que, también de nuevo, deben colaborar y movilizarse para optimizar así el proceso de producción y su calidad.

Es a partir de aquí donde se hacen más evidentes los efectos disciplinarios que sobre la organización y las condiciones de trabajo de los operadores tienen las políticas de aseguramiento de la calidad: que en las instrucciones de trabajo se establezcan los criterios de calidad a cumplir por parte de los componentes supone que, puesto que ahora los operadores directos son inmediatamente responsables de las funciones indirectas de verificación de la calidad, los trabajadores en el taller deben completar su actividad siguiendo necesariamente las pautas establecidas documentalmente en la procedimentalización del proceso, debiendo dejar las piezas y conjuntos sobre los que trabajan dentro de esos criterios de calidad establecidos para poder transferir el componente a la siguiente fase o estación productiva:

«Ahora es todo mucho más unitario, hay mucho más control de calidad implícito en el proceso, incluso después del montaje: no puedes seguir a menos que verifiques que tengas una serie de datos que autoricen o enciendan la luz verde para seguir montando y así sucesivamente» (director industrial, empresa Zuzendu). 
Se podría interpretar así la calidad como un enriquecimiento del trabajo a realizar por los operadores al haber sido gerencialmente capacitados para decidir si una pieza cumple o no lo establecido por el procedimiento de calidad, lo que podría suponer incrementar su autonomía y discrecionalidad sobre el proceso de trabajo, además de la eliminación de la anterior supervisión autoritaria de los mandos intermedios como verificadores de calidad. Sin embargo, la propia técnica o dispositivo de la trazabilidad permite matizar esta interpretación, ya que si la procedimentalización del proceso y la propia mejora continua suponían el establecimiento de un taylorismo participativo que expropia y reifica la inteligencia de producción movilizada por los trabajadores mediante su implicación en la mejora continua, la trazabilidad da lugar a la construcción de un nuevo dispositivo disciplinario de control total sobre la actividad de los trabajadores individualmente considerados.

Como veíamos, la trazabilidad se refiere a la identificación de no conformidades en un producto y a la localización de la fase productiva donde se ha fabricado ese error; pero, además de constituir una trazabilidad del producto, supone a la vez una trazabilidad del sujeto, la trazabilidad del trabajador: una vez que el operador termina una tarea debe comprobar que se ajusta a los criterios de calidad establecidos gerencialmente, cuyo cumplimiento indica que las operaciones se han realizado correctamente, debiendo a continuación el operador rellenar una «hoja o ficha de calidad» donde apunta las medidas obtenidas y su conformidad, haciéndose responsable de que, efectivamente, se cumplen las instrucciones al firmar con su propia rúbrica o número de empleado ese documento:

"Como tenemos una trazabilidad, que el sistema nos ha obligado a ser rígidos en ese sentido, nosotros tenemos un documento en que sabemos quién ha montado esa máquina. La trazabilidad consiste en que tú seas capaz, cuando tienes un problema, de echar para atrás y conocer el origen de la causa: para eso es necesario metodizar todo el montaje, hemos hecho unos métodos de montaje en los que intentamos que la gente sea estricta. Dentro de esos documentos tenemos unas pautas de control que el operario tiene que ir rellenando y firmando para que no se olvide nada, en todo caso que se equivoque, y después, como él va a tener que marcar allí que la pieza va con un valor determinado y la tiene que firmar, antes de indicar el valor mirará con seguridad que lo que pone lo está poniendo bien, porque luego yo, si voy a mirar para atrás, tengo que saber que tiene que salir con unos valores determinados. Puedes llegar al principio de la causa para saber qué acción tenemos que poner en marcha para buscar la solución. Eso es la trazabilidad» (director de Montaje, empresa Buruzagi).

El trabajador se hace así personal e individualmente responsable de que ese producto cumple las exigencias de calidad o, lo que es lo mismo, comunica que él mismo cumple o 
no las obligaciones procedimentalizadas, estableciendo si el operador trabajó o no de manera conforme: la trazabilidad garantiza no sólo que el producto es conforme, sino si el trabajador también lo es. Se hace así evidente el carácter implícitamente disciplinario del dispositivo de la trazabilidad, ya que cuando se detecta un error o no conformidad en el producto no sólo se puede rastrear «hacia atrás» dónde, en qué fase y en qué momento se ha producido el error, comprobando que, a pesar de que la hoja de calidad refleja la conformidad, ese parámetro no se cumple, sino, sobre todo, quién o qué trabajador se ha responsabilizado de dar conforme una operación que posteriormente ha provocado problemas productivos de calidad: se detecta, traza o rastrea así al culpable personal de esa no conformidad $^{25}$, lo que permite a la dirección valorar las causas por las que ese operador no ha trabajado con la calidad pertinente y tomar medidas para su disciplinamiento ${ }^{26}$.

Sin embargo, esta trazabilidad del sujeto no sólo funciona como dispositivo disciplinario a posteriori, una vez detectado el error, sino que tiene efectos de control del trabajo humano preventivos: puesto que los trabajadores son conscientes de que deben asumir personalmente la responsabilidad por el mecanizado y montaje de piezas y conjuntos a través de su firma de los documentos de calidad, se ven constreñidos necesariamente a cumplir las especificaciones y asegurarse de que su trabajo es conforme si quieren evitar que la dirección les pida explicaciones, no quedándoles más remedio que colaborar obligatoriamente en la consecución de la calidad establecida como recurso estratégico por la dirección, pudiendo ésta evaluar continuamente ( $y$, en su caso, reprobar disciplinariamente) el rendimiento del trabajador respecto a la calidad al analizar los registros de las «hojas de calidad» firmadas por cada operador 27 :

«Tengo que controlar una serie de medidas y criterios y responsabilizarme por escrito y con mi firma de que están dentro de las tolerancias exigidas por la oficina de producción. Así, si hay algún problema, pueden identificar inmediatamente dónde

\footnotetext{
25 Un buen ejemplo del carácter culpabilizador de la trazabilidad es el recogido por Lillrank (1995: 430) en la fábrica de Toyota en Tahara (Japón): «podría el señor Suzuki de la sección XYZ venir inmediatamente, hemos encontrado un defecto suyo».

26 «Las unidades o los lotes de fabricación deben mantener registros de trazabilidad, esto es, debemos poder relacionar las materias primas, las máquinas, los operarios que han intervenido y la fecha y la hora de cada unidad de producción. Este aspecto es importante para posteriormente estudiar las causas de los rechazos de algunos lotes o unidades producidas» (Badia y Bellido, 1999: 65).

27 Por ejemplo, en el Convenio Colectivo de la Industria Siderometalúrgica de Gipuzkoa (1997-1998), sintetizando el carácter disciplinador y procedimentalizador de la trazabilidad en el aseguramiento de la calidad, se enfatiza que: «En el caso de que los trabajos sean rechazados por el control de calidad, el trabajador que los realizó deberá efectuar la reparación o selección, corriendo a su costa el tiempo que esta labor emplee, sin perjuicio de las otras responsabilidades que le sean imputables. El trabajador no podrá realizar el trabajo de forma distinta a la que por el uso o norma escrita se tenga establecida sobre la forma de efectuar el autocontrol» (art. 17).
} 
se ha producido y quién ha cometido el error. Si alguna de mis piezas va mal, pueden venir a hablar conmigo y decirme que cambie alguna cosa, que qué pasa, ya sabes. Así se controla uno mismo, tienes más responsabilidad, pero también te controlan arriba más: al hacerte personalmente responsable de la pieza, no te queda más remedio que verificar bien la calidad» (operador-programador de centro de mecanizado n. ${ }^{\circ}$ 2, empresa Berritzaile).

"Antes la cantidad era lo más importante, ahora lo es la calidad; recibimos las piezas verificadas y luego yo me responsabilizo de mis piezas rellenando una ficha de calidad. Como nosotros en mecanizado servimos a montaje, ellos nos exigen más, no como antes que al final todo valía, ahora las piezas deben entregarse para montar directamente: si les mandas una pieza mal te lo pueden echar en cara a ti y rompe el compañerismo, lo mejor es hacerlo bien" (operador de centro de mecanizado $\mathrm{CNC} n .^{\circ} 2$, empresa Berritzaile).

De esta forma, si los organizadores de la producción no consiguieran construir efectivamente la nueva cultura organizativa de la calidad (un nuevo orden en la empresa) mediante la implicación interiorizada y «armoniosa» de los trabajadores en las actitudes de la calidad, en la mejora continua y en los objetivos empresariales, la trazabilidad como dispositivo disciplinario les permite controlar el trabajo humano y su actividad, al tiempo que forzar los comportamientos deseados gerencialmente por parte de los trabajadores en el taller (de ahí que la trazabilidad sea una tecnología social de acuñación y transformación de los comportamientos y prácticas de los sujetos; Ping, Ashmore y Mulkay, 1992), con lo que el concepto «responsabilidad» acuñado en la participación o empowerment adquiere organizativamente tanto un significado enriquecedor del trabajo humano como disciplinariamente inculpatorio, mediante la implantación de una especie de «gestión a través de la culpa» (management through blame), que puede llegar a la identificación y humillación pública del trabajador culpable (Delbridge y Turnbull, 1992; Legge, 1995: 45; Sewell y Wilkinson, 1992b: 105):

«Nosotros partimos de que el departamento de calidad es uno mismo. Por eso entendemos que el que hace, tiene que hacer bien, y para hacer bien en las partes importantes de los métodos de trabajo tenemos que marcar unas pautas en las cuales le decimos dentro de qué valores tienen que quedar los elementos montados, y él tiene que marcar ese elemento, el día que lo ha hecho y con el valor que ha quedado, y encima sabemos la persona. El único objetivo es saber qué ha hecho, pero no con ánimo de criticar, sino con ánimo de juntarnos con él y decirle que pusimos esto y nos hemos equivocado para intentar que no vuelva a pasar. Si no indicas eso, se ha cometido un fallo pero no sabes quién ni dónde se ha cometido el fallo, ahí te 
quedas, no puedes hacer nada más porque no puedes llegar más al fondo, porque si te juntas con él, ya sé dónde está el fallo, pasó esto, pero de la otra forma te quedas parado, tienes un problema pero no eres capaz de llegar al fondo. Tenemos que decir qué es lo que ha pasado, analizar la causa, y aplicar una acción correctiva con la que el problema no va a suceder, con eso consigues cerrar el círculo del fallo» (director de Montaje, empresa Buruzagi).

El diseño o construcción de estos dispositivos disciplinarios de trazabilidad por parte de los organizadores de la producción puede provocar la erosión o ruptura de las relaciones sociales de vinculación entre los componentes del obrero colectivo: puesto que ahora cada trabajador debe obligatoriamente responsabilizarse de los resultados y características de su actividad mediante su firma de las «hojas de calidad», que le inculpan si existe algún error o no conformidad, ninguno de ellos desea hacerse cargo de los errores cometidos por otro operador y de la solicitud de explicaciones por parte de la oficina técnica; de ahí que, por un lado, se individualice al máximo la actividad de trabajo y, por otro lado, cada trabajador exija a aquellos operadores que han intervenido en fases anteriores del proceso que se comprometan a cumplir con los parámetros (de calidad y producción) prescritos por la dirección para que él mismo pueda realizar fluidamente su trabajo. Precisamente, ésta es la lógica disciplinaria que sustenta la conversión gerencial de los trabajadores en «clientes internos» en la reorganización de los procesos de producción: cada trabajador debe constituirse y esforzarse en convertirse a sí mismo en un proveedor de calidad respecto al siguiente trabajador en el proceso productivo, garantizando que éste sea un «cliente satisfecho", y exigir simultáneamente a los demás trabajadores que le proveen a él o ella que cumplan también con los requisitos de calidad (Wilkinson y Willmott, 1995: 15), poniéndose en práctica así, a través de los comportamientos de la totalidad de esos trabajadores, ahora «clientes internos», los contenidos gerenciales acuñados en la nueva cultura organizativa de la calidad.

Esta individualización y «mercantilización entre clientes» ${ }^{28}$ de las relaciones entre los trabajadores provoca la ruptura de la «solidaridad de intereses» entre los operadores, erosiona las posibilidades de su movilización colectiva frente a la dirección, al tiempo que son ahora también los propios operadores los que se comportan como controladores y disciplinadores de sus propios compañeros (Fantasia, Clawson y Graham, 1988: 476-483), con lo que la dirección de estas empresas delega realmente en ellos su tradicional función de supervisión, cerrando así el dispositivo disciplinario que supone la trazabilidad de los productos y de los sujetos, es decir, los trabajadores se autocontrolan (y disciplinan) individual y

28 Sobre la mercantilización de las relaciones entre compañeros de trabajo en el interior de las empresas a través de la noción del «cliente interno» y su relación con procesos sociales y políticos globales del resurgimiento del pensamiento conservador liberal (de la «nueva derecha») en las dos últimas décadas, véase Tuckman (1995). 
colectivamente, se desmovilizan como grupo enfrentado a la dirección, se reduce el conflicto y se expropia su conocimiento empírico mediante su participación en la gestión de la calidad. Se trasladan los dispositivos de control desde el exterior del individuo a su interior, haciendo a cada uno responsable de su propio rendimiento mediante la manipulación gerencial de la subjetividad de los trabajadores fomentando una «individualidad automotivada» (Wilkinson y Willmott, 1995: 14; Willmott, 2001: 409).

Por todo ello, la trazabilidad supone emplear a favor de la empresa las tradicionales prácticas de regulación colectiva del grupo de trabajadores que anteriormente se usaban para «luchar contra la dirección» (Roy, 1952, 1953 y 1954; Burawoy, 1985)29. Ahora, mediante la trazabilidad, la dirección o el capital encauzan esa regulación obrera colectiva sancionadora en su beneficio al ser los propios trabajadores los que exigen a sus compañeros que cumplan los objetivos empresariales para evitar que, ante la supervisión disciplinaria final de la gerencia y su ingeniería de producción, «paguen justos por pecadores» (operador de montaje de centros de mecanizado, empresa Eskulan). El obrero colectivo, su conocimiento y regulaciones, queda manipulado y sometido a la dirección (Delbridge, Turnbull y Wilkinson, 1992: 102-104). Esta conversión de las relaciones colectivas entre los trabajadores en una red de clientes internos supone fundamentalmente construir una trama de autodisciplina colectiva y de vigilancia recíproca (Kerfoot y Knights, 1995: 228; Meek, 1988), un sistema disciplinario regulado por los principios individualistas del mercado que intenta suprimir las, peligrosas para la gerencia, posibilidades de «solidaridad de clase»:

«Por lo menos, sabes que en situaciones normales, si al final de año tú cobras algo más es porque tú te has partido el alma, y sin querer le implicas a él y al de al lado, y sin querer uno a otro se controlan, eliminas personas y mandos intermedios que hacian de controladores del personal, para trabajar a tiempos y primas, con estos sistemas tú a ti mismo haces un autocontrol y controlas a tu compañero de al lado, porque al de al lado le vas a decir igual: "al final de año cobramos cincuenta mil, si todos hacen lo que tú, cobramos veinte". Quitas una lucha de dirección. Es el romper el sistema piramidal y hacerlo plano. Que se gestionen ellos y que estén implicados en el proceso» (director de Mecanizados, empresa Berritzaile).

«Falta el compañerismo que había antes, ahora cada uno se preocupa sólo de lo suyo, de su trabajo y nada más. Tú solo te dedicas a lo tuyo, a hacerlo bien para que no te digan nada arriba y dejándoselo bien al siguiente para que no tenga que preocuparse de algo que hayas hecho mal tú. Yo hago lo mismo con los demás, si me

29 Por ejemplo, cuando un grupo obliga a los operadores a seguir sus reglas informales de frenado de la producción bajo la amenaza de «sanciones sociales» a los «intensificadores del ritmo» (Lahera Sánchez, 2000: capítulo 4). 
viene algo mal se lo digo a quien sea, porque no puedo perder ni mi tiempo ni mi calidad» (operador de torno CNC, empresa Zuzendu).

"Aunque se sabe de quién es cada pieza, he decidido marcar mis piezas con un sello personal [una marca realizada con un cincel en una cara de cada pieza mecanizada] para que no me adjudiquen, por error o por otra cosa, alguna que no he hecho yo, y que si hay problemas se responsabilice el que lo haya hecho" (operador de fresadora $\mathrm{CNC}$ n. ${ }^{\circ}$ 2, empresa Zuzendu).

\section{CONCLUSIÓN}

Como se ha ido señalando a lo largo de este texto, estas políticas participativas de aseguramiento de la calidad diseñadas e implantadas por las gerencias de las empresas fabricantes de máquinas-herramienta analizadas se centran en lograr un mayor control gerencial sobre la actividad real de los trabajadores y, simultáneamente, posibilitar una integración o implicación «moral» más intensa de éstos en la consecución de los objetivos empresariales, todo ello mediante la fabricación de una cultura organizativa de la calidad acuñada actitudinalmente en los propios trabajadores.

De esta forma, la actualización de la organización del trabajo taylorista incorporada en la normativa ISO 9000 para el aseguramiento y trazabilidad de la calidad supone, por tanto, diseñar un nuevo dispositivo disciplinario que pretende intervenir en el perpetuo conflicto histórico entre los organizadores de la producción y los trabajadores: el objetivo último de las prácticas participativas o de empowerment analizadas supone reorganizar los dispositivos de control gerenciales para eliminar o minimizar las oportunidades y habilidades de resistencia de los trabajadores (individualizando y mercantilizando las relaciones entre los propios trabajadores), así como para alterar o manipular sus percepciones sobre lo perjudicial e infundado de su oposición (Edwards, 1979: 16). El aseguramiento participativo de la calidad se construye así como el enésimo intento de resolver el principal problema del management, la incertidumbre del trabajo humano (Boyer y Freyssenet, 1996): que los trabajadores trabajen efectivamente como las gerencias desean que trabajen y con la máxima intensidad posible ${ }^{30}$.

Para ello, los contenidos construidos gerencialmente en la cultura organizativa de la calidad configuran un sistema de control para la obtención de los comportamientos deseados

30 El problema clave que deben enfrentar los organizadores de la producción para gestionar la incertidumbre del trabajo humano supone que: «El capitalista o el gerente pueden ordenar al trabajador hacer algo, pero ¿cómo pueden realmente lograr que el trabajador lo haga, y que lo haga bien y rápidamente? » (Friedman, 1977: 77). 
de los trabajadores mediante la coordinación e integración simultánea en un único dispositivo, las propias normas de calidad ISO 9000, de la dirección, la evaluación y el disciplinamiento gerencial de la actividad de los trabajadores (Edwards, 1979). Por un lado, este sistema de normas permite, a través de sus procedimientos de actuación (como se presentó en el epígrafe 3.1 de este artículo), definir la dirección del trabajo, es decir, dirigir las tareas a realizar, especificar las necesidades a satisfacer por el proceso de producción, establecer su orden, su precisión y su desarrollo temporal; por otro lado, estas normas incorporan sincrónicamente la evaluación o el procedimiento por el cual se supervisa y se establece la corrección o no conformidad del proceso productivo, tal y como establecen sus instrucciones de trabajo de obligado cumplimiento, mientras permite también medir el rendimiento de cada trabajador, así como identificar, en este caso mediante el dispositivo culpabilizador de la trazabilidad, al trabajador o grupos de trabajadores que no están desarrollando sus tareas prescritas adecuadamente; por último, estas normas son también un dispositivo para disciplinar a los trabajadores y lograr así, a través de la interiorización «moral» e ideológica de su implicación en la nueva cultura organizativa de la calidad, su cooperación, reforzando su aceptación de los objetivos gerenciales y su organización del trabajo (Edwards, 1979: 18).

Ahora bien, este aseguramiento de la calidad no sólo permite dirigir, evaluar y disciplinar la actividad de los trabajadores, sino que, a través de su implantación mediante las prácticas participativas del empowerment, pretende velar u ocultar sus trazos opresivos e intensificadores (desde el taylorismo participativo de la mejora continua a la propia vigilancia exhaustiva por la trazabilidad) mediante el modelado actitudinal de la propia personalidad de los trabajadores al recompensar y admitir tan sólo sus comportamientos de implicación, de lealtad, de adhesión, de conformidad y de compromiso con el orden productivo definido y controlado gerencialmente. De esta forma, la participación en el aseguramiento de la calidad como nuevo dispositivo o sistema de control pretende dominar totalizadoramente el comportamiento de los trabajadores, de los nuevos «trabajadores de calidad», mediante una conversión ideológica que sustituya su tradicional subjetividad conflictiva, como gran temor de la gerencia, por un fuerte vínculo recíproco de supuestos intereses mutuos: «la empresa reclama el alma de los trabajadores, o al menos la identidad de los trabajadores» (Edwards, 1979: 150-152).

De hecho, esta implicación ideológica deseada gerencialmente se refleja nuevamente en que el aseguramiento de la calidad permite, mediante este único dispositivo de las normas ISO 9000, sintetizar dos formas tradicionales, y originalmente contrapuestas, de control gerencial del trabajo: la autonomía responsable y el control directo (Friedman, 1977). «Autonomía responsable», cuando la nueva cultura de la calidad es aceptada y asumida por los trabajadores, al delegar o capacitar a éstos para tomar autóno- 
mamente (limitadas) decisiones productivas (empowerment), responsabilizándoles de su eficacia o inutilidad para mejorar el proceso productivo y reconociéndoles una nueva posición como gestores inteligentes de éste, cooptándoles ideológica y moralmente, pero también culpabilizándoles del resultado de sus acciones. Al mismo tiempo, «control directo» por parte de la gerencia al mantenerse la absoluta procedimentalización taylorista del proceso de trabajo en el aseguramiento de la calidad, así como las amenazas de sanción y la supervisión exhaustiva de los resultados, de la actividad de cada trabajador, de sus conformidades o no conformidades (mediante el management through blame incorporado en el fenómeno de la trazabilidad), lo cual garantiza el mantenimiento de una estrecha vigilancia gerencial en el caso de que su ingeniería cultural se vea frustrada por la ausencia de convencimiento o aceptación por parte de los trabajadores de las nuevas actitudes y comportamientos de adhesión e implicación vinculados a la propia cultura organizativa de la calidad (Friedman, 1977: 78-99). La simultaneidad de estas dos formas de control en los dispositivos de aseguramiento participativo de la calidad es lo que permite así a la gerencia contra-actuar, intentando contener o reconducir así la tradicional habilidad colectiva de resistencia de los trabajadores hacia la colaboración individualizada con la gerencia mediante su socialización en la cultura organizativa de la implicación.

Por tanto, la evaluación crítica de estas dimensiones y componentes incorporados en las políticas de participación de los trabajadores en el aseguramiento de la calidad total implica que estas prácticas de empowerment se construyen gerencialmente no como una estrategia de mejora de las condiciones de trabajo y de recualificación de los trabajadores, para mejorar efectivamente su soberanía productiva y conocimientos, sino como un nuevo dispositivo disciplinario, que delega y exige responsabilidad al taller pero, simultáneamente, recentraliza y refuerza el poder gerencial de supervisión (Hardy y Leiba-O'Sullivan, 1998: 470-475). Todo ello mediante un discurso gerencial participativo que pretende legitimar este nuevo sistema de control diseñado prometiendo la adquisición de poder en la toma de decisiones productivas por parte de los trabajadores, pero limitando detalladamente en la práctica sus márgenes de discrecionalidad, distorsionando así su supuesto contenido democratizador para proteger y mantener las desiguales relaciones de poder y dominio dentro de la empresa (Potterfield, 1999). A pesar de la retórica, se implanta muy poco empowerment en la práctica (Edwards y Collinson, 2002; Hales, 2000), lo que puede, como se ha demostrado en otro lugar (Lahera Sánchez, 2000b), socavar el compromiso de los trabajadores gerencialmente deseado si finalmente sus esperanzas participativas acaban siendo frustradas, al descubrir éstos subjetivamente los contenidos restrictivos y detalladamente disciplinarios de este tipo de participación fabricada por los organizadores de la producción: «el empowerment no parece tener las consecuencias que se reclama poseer» (Harley, 1999: 59). 
En definitiva, las prácticas participativas rastreadas en estas empresas fabricantes de máquinas-herramienta suponen la construcción de un nuevo dispositivo disciplinario para incrementar la frontera de control de la gerencia sobre la actividad de los trabajadores, buscando controlar, a través de una especie de «cruzada o ingeniería cultural» que manipula sus conciencias y prácticas (Kunda, 1992), los significados del tradicional vínculo conflictivo entre capital y trabajo mediante su neutralización a favor de la «participación» de los trabajadores, de que se hagan partícipes, en una especie de comunitarismo o reciprocidad industrial (Mills, 1948), redefiniendo así los valores y actitudes individuales con los que los trabajadores deberían relacionarse con los patronos (Keenoy y Anthony, 1992: 234-249; Smith, 1989): «No es una alternativa al taylorismo, sino una solución a su clásico problema de la resistencia de los trabajadores a poner su conocimiento de la producción al servicio de la racionalización» (Dohse et al., en Delbridge y Turnbull, 1992: 68), un medio para pacificar a la fuerza de trabajo, para desmovilizar a los trabajadores (Potterfield, 1999; Willmott, 2001: 395-397) $)^{31}$. Todo lo cual permite mantener los objetivos empresariales de control, extracción y manipulación de sus saberes e inteligencia de producción clandestinos, socializando una nueva lógica de la implicación, pero manteniendo los principios paradigmáticos de la organización del trabajo taylorista (Linhart, 1990: 31), sin alterar la intensamente asimétrica distribución de poder en la toma de decisiones productivas entre organizadores de la producción y trabajadores.

\section{BIBLIOGRAFÍA}

ADLER, P., y COLE, R. E. (1995): «Designed for learning: a tale of two plants», en A. Sandberg, Enriching production, Aldershot, Avebury, pp. 157-177.

AENOR (1994): Normas para la gestión y el aseguramiento de la calidad ISO-9000.

AFM (1985): Plan de Relanzamiento Excepcional del Sector de la Máquina-Herramienta, Donostia, 125 pp.

- (1990): Plan Sectorial de Máquinas-Herramienta, Donostia, 145 pp.

ANDERSEN CONSULTING-GOBIERNO VASCO (1990): Plan Sectorial Máquina-Herramienta, Bilbao, 51 pp.

ARGYRIS, C. (1998): «Empowerment: The emperor's new clothes», Harvard Business Review, mayo-junio, pp. 98-105.

BADHAM, R., y JÜRGENS, U. (1998): «Images of good work and the politics of teamwork», Economic and Industrial Democracy, vol, 19, n. ${ }^{\circ}$, Special Issue on «Good Work and Productivity», pp. 33-58.

BADIA, A. (1998): Calidad: enfoque ISO-9000, Bilbao, Deusto.

31 De hecho, para algunos representantes actuales de las teorías del labour process, el aseguramiento de la calidad total supone la culminación «bravermaniana» de la degradación del trabajo en el siglo xx (Tuckman, 1995: 74): «Bajo el disfraz de otorgar más autonomía al individuo que las organizaciones gobernadas por reglas burocráticas, la cultura organizativa amenaza con promover un nuevo e hipermoderno autoritarismo que, potencialmente, es más insidioso y siniestro que su predecesor burocrático» (Willmott, 2001: 415). 
BADIA, A., y BELLIDO, S. (1999): Técnicas para la gestión de la calidad, Madrid, Tecnos.

BERGGREN, C. (1992): Alternatives to lean production, Nueva York, ILR Press.

BIJKER, W. E., y LAW, J. (1992): Shaping Technology/Building Society, Massachusetts, MIT Press.

BLANCHARD, K.; CARLOS, J., y RANDOLPH, A. (1996): Empowerment takes more than a minute, San Francisco, Berret-Koelher Publishers.

BLYTON, P., y TURNBULL, P. (1992): Reassessing Human Resource Management, Londres, Sage.

BONAVIA, T., y QUINTANILLA, I. (1999): “Creencias directivas y participación de los empleados», Revista de Psicología del Trabajo y de las Organizaciones, vol. 15, n. ${ }^{\circ}$ 3, pp. 367-383.

BONAZZI, G. (1993): «Modelo japonés, toyotismo, producción ligera: algunas cuestiones abiertas», Sociología del Trabajo, n. ${ }^{\circ} 18$, pp. 3-22.

BOYER, R., y FREYSSENET, M. (Programa GERPISA) (1996): «Emergencia de nuevos modelos industriales», Sociología del Trabajo, n. ${ }^{\circ}$ 27, pp. 23-54.

- (2001): «El mundo que cambió la máquina. Un nuevo esquema de análisis de la industria del automóvil», Sociología del Trabajo, n. ${ }^{\circ} 41$, pp. 3-45.

BURAWOY, M. (1985): El consentimiento en la producción, Madrid, Ministerio de Trabajo.

CASTILLO, J. J. (ed.) (1991): Las nuevas formas de organización del trabajo, Madrid, Ministerio de Trabajo (2. ${ }^{a}$ ed.).

- (1996): «Fabricando la organización del trabajo de mañana: una fábrica líder en la mecánica», Sociología del Trabajo, n. ${ }^{\circ} 27$, pp. $55-76$

- (1997): Sociología del Trabajo. Un proyecto docente, Madrid, CIS.

- (1998): A la búsqueda del trabajo perdido, Madrid, Tecnos.

- (con la colaboración de Lahera Sánchez, A.) (1999): El trabajo del futuro, Madrid, Editorial Complutense.

CASTILLO, J. J., y PRIETO, C. (1991): Condiciones de trabajo, Madrid, CIS (2. ${ }^{a}$ ed.).

CASTILLO MENDOZA, C. A. (1990): «Control y organización capitalista del trabajo», Sociología del Trabajo, n. ${ }^{\circ} 9$, pp. 117-139.

— (1991): «Presentación», en J. P. Gaudemar, El orden en la producción, Madrid, Trotta, pp. 9-32.

CLAWSON, D., y FANTASIA, R. (1983): «Beyond Burawoy: the dialectics of conflict and consent on the shop floor», Theory and Society, vol. 12, pp. 671-680.

CLUTTERBACK, D. (1994): The power of empowerment, Londres, Kogan Page.

COLE, R. E. (1985): «The macropolitics of organizational change: a comparative analysis of the spread of small-group activities», Administrative Science Quarterly, vol. 30, pp. 560-585.

CONTI, R. F., y WARNER, M. (1993): «Taylorism, new technology and just-in-time systems in Japanese manufacturing», New Technology, Work and Employment, vol. 8, n. ${ }^{\circ}$, pp. 31-42.

Convenio Colectivo de la Industria Siderometalúrgica de Gipuzkoa 1997-1998.

Convenio Colectivo del Metal en Álava 1997-1999. 
CRESSEY, P., y DI MARTINO, V. (1991): Agreement innovation. The international dimension of technical change, Londres, Prentice Hall.

CUNNINGHAM, I.; HYMAN, J., y BALDRY, C. (1996): «Empowerment: the power to do what?», Industrial Relations Journal, vol. 27, n. ${ }^{\circ}$ 2, pp. 143-154.

DEAL, T., y KENNEDY, A. (1986): Culturas corporativas. Ritos y rituales de la vida organizacional, México, Fondo Educativo Interamericano.

DELBRIDGE, R., y TURNBULL, P. (1992): «Human Resource Maximization: The management of labour under just-intime manufacturing systems», en P. Blyton y P. Turnbull, Reassessing Human Resource Management, Londres, Sage, pp. 56-73.

DELBRIDGE, R.; TURNBULL, P., y WILKINSON, B. (1992): «Pushing back the frontiers: management control and work intensification under JIT/TQM factory regimes», New Technology, Work and Employment, vol. 7, n. ${ }^{\circ} 2$, pp. 97-106.

DURAND, J. P. (1998): «Is the "better job" still possible today?», Economic and Industrial Democracy, vol. 19, n. ${ }^{\circ} 1$, Special Issue on "Good Work and Productivity», pp. 185-198.

DURAND, J. P.; STEWART, P., y CASTILLO, J. J. (1999): Teamwork in the automobile industry. Radical change or passing fashion?, Londres, MacMillan Press.

EDWARDS, P., y COLLINSON, M. (2002): «Empowerment and managerial labor strategies», Work and Occupations, vol. 29, n. $^{\circ}$, pp. $272-299$.

EDWARDS, R. (1979): Contested terrain. The transformation of the workplace in the twentieth century, Nueva York, Basic Books.

ELMES, M., y SMITH, C. (2001): «Moved by the Spirit: Contextualizing workplace empowerment in American spiritual ideals», Journal of Applied Behavioural Sciences, vol. 17, n. ${ }^{\circ}$ 1, pp. 33-50.

FANTASIA, R.; CLAWSON, D., y GRAHAM, G. (1988): «A critical view of worker participation in American industry», Work and Occupations, vol. 15, n. $^{\circ} 4$, pp.468-488.

FOUCAULT, M. (1976): Vigilar y castigar, Madrid, Siglo XXI.

FRIEDMAN, A. L. (1977): Industry and Labor. Class struggle at work and monopoly capitalism, Londres, MacMillan Press.

GARCÍA CALAVIA, J. (1999): «La "reprofesionalización” del trabajo: ¿una nueva panacea tecnológica?», Sociología del Trabajo, n. ${ }^{\circ}$ 36, pp. 35-56.

GAUDEMAR, J. P. de (1991): El orden en la producción, Madrid, Trotta.

GOBIERNO VASCO-Eusko Jaurlaritza (1992): Programa de Competitividad del Clúster de Máquina-Herramienta, Bilbao, documento confidencial, $117 \mathrm{pp}$.

- (1994): Clúster de Máquina-Herramienta: Una visión para el futuro, Bilbao, Programa de Competitividad de Euskadi, $90 \mathrm{pp}$.

GRAHAM, L. (1995): On the line at Subaru-Isuzu, Nueva York, ILR/Cornell Univ. Press.

GREGORY, K. L (1983): «Native view paradigms: Multiple cultures and culture conflicts in organizations», Administrative Science Quarterly, vol. 28, pp. 359-376.

GUEST, D. (1995): «Human Resource Management, Trade Unions and industrial relations», en J. Storey, Human Resource Management. A critical text, Londres, Routledge, pp. 110-141. 
HALES, C. (2001): «Management and empowerment programmes», Work, Employment and Society, vol. 14, n. ${ }^{\circ} 3$, pp. 501-519.

HARDY, C., y LEIBA-O'SULLIVAN, S. (1998): «The power behind empowerment: Implications for research and practice», Human Relations, vol. 51, n. ${ }^{\circ}$, pp. 451-483.

HARLEY, B. (1999): «The myth of empowerment: Work organization, hierarchy and employee autonomy in contemporary Australian workplaces», Work, Employment and Society, vol. 13, n. ${ }^{\circ}$ 1, pp. 41-66.

HYMAN, J., y MASON, B. (1995): Managing employee involvement and participation, Londres, Sage.

INFESTAS, A. (1991): Sociología de la empresa, Salamanca, Amarú Ediciones.

JONES, O. (1997): «Changing the balance? Taylorism, TQM and work organization», New Technology, Work and Employment, vol. 12, n. $^{\circ} 1$, pp. $13-24$.

KEENOY, T., y ANTHONY, P. (1992): «HRM: metaphor, meaning and morality», en P. Blyton y P. Turnbull, Reassessing Human Resource Management, Londres, Sage, pp. 233-255.

KERFOOT, D., y KNIGHTS, D. (1995): «Empowering the "quality worker”?», en A. Wilkinson y H. Willmott, Making quality critical, Londres, Routledge, pp. 219-239.

KERN, H., y SCHUMANN, M. (1988): El fin de la división del trabajo, Madrid, Ministerio de Trabajo.

KILLMAN, R. H.; SAXTON, M. J., y SERPA, R. (eds.) (1985): Gaining control of the corporate culture, San Francisco, Jossey Bass.

KOCHAN, T., y DYER, L. (1995): «HRM: An American view», en J. Storey, Human Resource Management. A critical text, Londres, Routledge, pp. 332-351.

KUNDA, G. (1992): Engineering Culture. Control and Commitment in a High-Tech Corporation, Philadelphia, Temple University Press.

LAHERA SÁNCHEZ, Arturo (2000a): La emergencia de nuevos modelos productivos y la participación de los trabajadores: Diseño e implantación de conceptos antropocéntricos de producción en empresas fabricantes de máquinasherramienta, Tesis doctoral, Departamento de Sociología III, Universidad Complutense de Madrid, 714 pp. Dirigida por Juan José Castillo.

- (2000b): «La emergencia de nuevos modelos productivos: la participación de los trabajadores y la fabricación del consentimiento en la producción», Revista de Dialectología y Tradiciones Populares (CSIC), tomo LV, cuaderno segundo, pp. 9-50.

- (2001): «La participación de los trabajadores en la empresa: ¿hacia la democratización de las relaciones industriales? Una propuesta metodológica de análisis», en A. Fernández Steinko y D. Lacalle (eds.), Sobre la democracia económica. La democracia en la empresa, Barcelona, El Viejo Topo y Fundación de Investigaciones Marxistas, pp. 61-138.

- (2003): «Gestión participativa de los recursos humanos en empresas fabricantes de máquinas-herramienta: Una evaluación crítica de la participación de los trabajadores», Inguruak, n. ${ }^{3}$ 35, pp. 101-136.

- (2004): La participación de los trabajadores en la democracia industrial, Madrid, La Catarata.

LEGGE, K. (1995): «HRM: Rhetoric, reality and hidden agendas», en J. Storey, Human Resource Management. A critical text, Londres, Routledge, pp. 33-59.

LEITE, M. de P. (1999): “Nuevos desafíos en el mundo del trabajo», Sociología del Trabajo, n. 36, pp. 3-31. 
LILLRANK, P. (1995): “Social preconditions for lean management and its further development», en A. Sandberg, Enriching production, Aldershot, Avebury, pp. 427-437.

LINHART, D. (1990): «¿Qué cambios en la empresa?», Sociología del Trabajo, n. 11, pp. 25-48.

- (1997a): La modernización de las empresas, Buenos Aires, Asociación Trabajo y Sociedad.

- (1997b): «El trabajo y el empleo en Francia. Algunos elementos del debate científico», Sociología del Trabajo, n. ${ }^{\circ} 31$, pp. $15-36$.

MARTÍN CRIADO, E., e IZQUIERDO MARTÍN, J. (1993): «Elementos para una sociología económica de la gestión empresarial de la fuerza de trabajo», Sociología del Trabajo, n. ${ }^{\circ} 17$, pp. 121-145.

MARX, K. (1979): El capital, Madrid, Siglo XXI.

McARDLE, L.; ROWLINSON, M.; PROCTER, S.; HASARD, J., y FORRESTER, P. (1995): «Total Quality Management and participation», en A. Wilkinson y H. Willmott, Making quality critical, Londres, Routledge, pp. 156-172.

MEEK, V. L. (1988): “Organizational culture. Origins and weaknesses», Organization Studies, vol. 9, n. ${ }^{\circ}$ 4, pp. $453-473$.

MILLER, P., y O'LEARY, T. (1994): «The factory as a laboratory», Science in Context, vol. 7, n. ${ }^{\circ}$ 3, pp. 469-496.

MILLS, C. W. (1948): «The contribution of sociology to studies of industrial relations», Industrial Relations Research Association, pp. 199-222.

MORALEDA, F. (1994): «Empowerment. Cuando el poder fluye en la empresa», Capital Humano, n. ${ }^{\circ} 104$, pp. $18-22$.

MURRELL, K., y MEREDITH, M. (2002): Empowering Employees, Nueva York, McGraw-Hill.

OGBONNA, E. (1992): «Organization culture and Human Resource Management: Dilemmas and contradictions», en P. Blyton y P. Turnbull, Reassessing Human Resource Management, Londres, Sage, pp. 74-96.

OMPES-FUENLABRADA (1998): Guía práctica para la implantación de un Sistema de Calidad ISO 9000, Ayuntamiento de Fuenlabrada.

OUCHI, W. (1982): Teoría Z, Barcelona, Orbis.

PANIAGUA LÓPEZ, J. A. (1999): «La calidad total: nuevas formas de nombrar al taylorismo», Sociología del Trabajo, n. ${ }^{\circ} 37$, pp. $41-58$.

PETERS, T., y WATERMAN, R. (1982): In search of excellence, Nueva York, Random House.

PICKARD, J. (1994): «El verdadero significado del empowerment», Capital Humano, n. ${ }^{\circ}$ 65, pp. 59-67.

PING, T.; ASHMORE, M., y MULKAY, M. (1992): «Technology, testing, text: clinical budgeting in the U.K. National Health service», en W. E. Bijker y J. Law, Shaping Technology/Building Society, Massachusetts, MIT Press, pp. 265-289.

POTTERFIELD, T. A. (1999): The business of employee empowerment: Democracy and ideology in the workplace, Westport, Quorum Books.

RAMSAY, H. (1977): "Cycles of control: worker participation in sociological and historical perspective», Sociology, vol. 11, n. ${ }^{\circ}$, pp. 481-506.

REYGADAS, L. (2002): Ensamblando culturas, Barcelona, Gedisa.

ROBERTS, K., y CORCORAN-NANTES, Y. (1995): «TQM, the new training and industrial relations», en A. Wilkinson y H. Willmott, Making quality critical, Londres, Routhledge, pp. 194-218. 
ROY, D. (1952): "Quota restriction and goldbricking in a machine shop», American Journal of Sociology, vol. 57, pp. 427-442.

- (1953): «Work satisfaction and social reward in quota achievement», American Sociological Review, vol.18, pp. 507-514.

- (1954): «Efficiency and the fix», American Journal of Sociology, vol. 60, n. ${ }^{\circ}$ 3, pp. 255-266.

- (1980): «Book review of Michael Burawoy's Manufacturing consent», Berkeley Journal of Sociology, vol. 23, pp. 329-339.

SANDBERG, A. (1995): Enriching production, Aldershot, Avebury.

- (1998): «Good work and productivity», Economic and Industrial Democracy, vol. 19, n. ${ }^{\circ}$, Special Issue on «Good Work and Productivity», pp. 5-16.

SARRIÉS, L. (1994): Nuevos modelos de organización industrial: un análisis sociológico, Madrid, Dykinson.

SCHEIN, E. (1985): La cultura empresarial y el liderazgo, Barcelona, Plaza y Janés.

SCHIED, F.; CARTER, V.; PRESTON, J., y HOWELL, S. (1997): “Knowledge as "quality non-conformance”: A critical case study of ISO 9000 and adult education in the workplace», texto presentado en Adult Education Research Conference, $6 \mathrm{pp}$.

SCHUMANN, M. (1998): «New concepts of production and productivity», Economic and Industrial Democracy, vol. 19, n. ${ }^{\circ}$, Special Issue on «Good Work and Productivity», pp. 17-32.

- (1999): «El desarrollo del trabajo industrial: nuevas contradicciones», en J. J. Castillo, El trabajo del futuro, Madrid, Editorial Complutense, pp. 83-97.

SEGRESTIN, D. (1997): «L'entreprise à l'épreuve des normes de marché», Revue Française de Sociologie, vol. 1, pp. 553-585.

SELS, L. (1997): «Timeless crafmanship? New production concepts in the machine tool industry», Work, Employment and Society, vol. 11, n. ${ }^{\circ} 4$, pp. 663-684.

SENLLE, A., y STOLL, G. (1995): Calidad total y normalización: ISO 9000, Barcelona, Gestión 2000.

SEWELL, G. (2001): «What goes around, comes around. Inventing a mythology of teamwork and empowerment», Journal of Applied Behavioural Sciences, vol. $37, \mathrm{n} .{ }^{\circ}$ 1, número monográfico sobre History of Workplace Empowerment, pp. 70-89.

SEWELL, G., y WILKINSON, B. (1992): “"Someone to watch over me”. Surveillance, discipline and the just-in-time labour process», Sociology, vol. 26, n. ${ }^{\circ}$ 2, pp. 271-298.

- (1992b): «Empowerment or emasculation? Shopfloor surveillance in a Total Quality organization», en P. Blyton y P. Turnbull, Reassessing Human Resource Management, Londres, Sage, pp. 97-115.

SMITH, C. (1989): «Flexible specialization, automation and mass production», Work, Employment and Society, vol. 3 , n. ${ }^{\circ}$, pp. 203-220.

SPRI (1994): Informes básicos sectoriales de la Comunidad Autónoma del País Vasco: Máquina-herramienta, Bilbao.

STOREY, J. (1995): Human Resource Management. A critical text, Londres, Routledge.

STRAUSS, G., y ROSENSTEIN, E. (1970): «Workers participation: a critical view», Industrial Relations, vol. 9, pp. 197-214. 
TAYLOR, F. W. (1914): Declaración ante la United States Commission on Industrial Relations; Cámara de Representantes, Washington, DC.

- (1925): La dirección de los talleres, Barcelona, Feliu y Susanna.

- (1970): Principios de la administración científica, Barcelona, Oikos.

THOMPSON, P., y WARHURST, C. (eds.) (1998): Workplaces of the future, Basingstoke, MacMillan.

TUCKMAN, A. (1995): «Ideology, quality and TQM», en A. Wilkinson y H. Willmott, Making quality critical, Londres, Routledge, pp. 54-81.

WILKINSON, A. (1998): «Empowerment: theory and practice», Personnel Review, vol. 27, n. ${ }^{1}$, pp. 40-56.

WILKINSON, A., y WILLMOTT, H. (1995): Making quality critical, Londres, Routledge.

WILLIAMS, K.; HASLAM, C.; WILLIAMS, J., y CUTLER, T. (1992): «Against lean production», Economy and Society, vol. 21, n. ${ }^{\circ}$, pp. 321-354.

WILLMOTT, H. (2001): «Strength is ignorance: slavery is freedom. Managing culture in modern organizations», en Warwick Organizational Behaviour Staff, Organizational Studies. Critical perspectives on business and management, Londres, Routledge, vol. 1, pp. 386-426.

WOMACK, J. P; JONES, D.T., y ROOS, D. (1991): The machine that changed the world, Nueva York, Harper Collins.

YATES, C.; LEWCHUCK, W., y STEWART, P. (2001): «Empowerment as a Trojan horse: New systems of work organization in the North American automobile industry", Economic and Industrial Relations, vol. 22, pp. 517-541. 
During the last decade, Social Sciences of Work have developed a wide academic and business debate on the possible emergence of new industrial models in companies, centred on the introduction of organizational or business cultures that allegedly break away from traditional taylorist work organization practices. Outstanding among these transformations is managerial backing for the establishment of participatory management of human resources (empowerment) which makes it possible, on the one hand, to take advantage of the empirical knowledge of employees in the improvement and perfecting of manufacturing processes and, on the other hand, guarantee their greater involvement in the achievement of business objectives, through the design of a new 'organizational culture of quality'. This participation, which is centred on autonomy in the job, is the base on which a new competitive strategy is being constructed, based on production quality assurance policies, which are giving rise to transformations in the mechanisms for organization and managerial inspection of work. However, the actual result of this achievement of quality has involved the design and introduction of new taylorist practices and increased watchfulness over employee performance, and so the managerial definition of participation has fashioned, and restricted, this as a device for expropriation of employees' knowledge and experience, at the same time as it has meant the construction of a new discipline and system of detailed control of their productive performance and an intensification of their activity, as illustrated by the real contents of productive and organizational restructuring policies carried out in companies that manufacture machine-tools in the Basque Country during the second half of the nineties (1994-2000).

Key words: Workers' Participation, Total Quality, Taylorism, Industrial Models, Industrial Discipline, Corporate Culture, Empowerment, Machine-Tools. 